\title{
Apontamentos sobre a atribuição de vasos áticos: a produção do Pintor de Gela*
}

DIAS, C.K.B. Apontamentos sobre a atribuição de vasos áticos: a produção do Pintor de Gela. Revista do Museu de Arqueologia e Etnologia, São Paulo, 19: 235-255, 2009.

Resumo: No início do século XX, J. D. Beazley lançou as bases definitivas para a metodologia de atribuição de vasos áticos. Ao longo dos anos, os vasos cerâmicos foram ligados a mãos de artistas nomeados convencionalmente, como o Pintor de Gela, um artista ático que operou em Atenas entre fins do século VI e meados do $\mathrm{V}$ a.C., assim batizado porque a maior parte de seus vasos foi encontrada na Sicília, especialmente em Gela. A este Pintor foram ligados mais de 350 vasos, atribuídos de diversas maneiras à sua mão, à sua maneira ou à sua oficina. Porém, algumas dessas atribuições se apresentaram imprecisas ou, de fato, equivocadas. Procuramos sistematizá-las e corrigi-las a fim de compreendermos a produção deste artista de maneira completa, inserido no contexto da produção cerâmica ática de seu período.

Palavras-chave: Cerâmica ática - Figuras negras - Pintor de Gela - Atribuição.

$\mathrm{N}$ este artigo discutimos a atribuição de vasos cerâmicos ao Pintor de Gela, o artista ático produtor de lécitos de figuras negras mais prolífico no período que vai da última década do século VI a meados do século V a.C. Pertencente à geração de pintores tradicionalistas que produziu vasos de figuras negras quando a técnica de figuras

$\left({ }^{*}\right)$ Artigo baseado nos resultados da tese de doutorado intitulada "O Pintor de Gela. Características formais e estilísticas, decorativas e imagéticas”, desenvolvida durante os anos de 2004 a 2009, sob orientação da Profa. Dra. Haiganuch Sarian, no programa de PósGraduação do Museu de Arqueologia e Etnologia, Universidade de São Paulo, com apoio FAPESP. $\left.{ }^{* *}\right)$ Doutora em Arqueologia pelo Museu de Arqueologia e Etnologia da Universidade de São Paulo. vermelhas fora introduzida e adotada por diversos artistas na Ática, este artista recebeu esse nome porque a maioria de seus vasos foi encontrada na Sicília, sobretudo em Gela. Encontra-se na bibliografia a idéia de que o Pintor pudesse ser originalmente um siciliota emigrado a Atenas que manteve suas conexões comerciais com seu país de origem, o que poderia explicar a abundância de vasos atribuídos a ele encontrados na Sicília.

O Pintor de Gela demonstra qualidades artísticas interessantes e importantes que devem ser observadas: a originalidade com que produziu vasos nos quais se percebe a preocupação com simetria, volume, profundidade e proporção; a introdução de técnicas originais como o agrupamento vertical das imagens; sua capacidade de abstração e de ordenação de imagens; a manuten- 
DIAS, C.K.B. Apontamentos sobre a atribuição de vasos áticos: a produção do Pintor de Gela. Revista do Museu de Arqueologia e Etnologia, São Paulo, 19: 235-255, 2009.

ção de um coeso repertório temático, ao qual, vez ou outra, incluiu novas interpretações.

A produção deste artista mereceu uma revisão e novas interpretações. O que foi publicado sobre o Pintor de Gela é muito pouco em relação à sua importância como artista pertencente a um período tão produtivo da arte grega. Apontamentos sobre qualidade artística, estilo, produção, iconografia, cronologia e atribuição puderam ser feitos a partir do estudo sistemático de seus vasos, inseridos no universo dos artistas e da produção de vasos áticos de figuras negras. $\mathrm{O}$ conhecimento de sua produção, tanto nos níveis formal quanto imagético, contribuiu para uma caracterização e maior conhecimento do desenvolvimento técnico e artístico pelos quais passou a cerâmica ática de figuras negras, permitindo questionamentos sobre o que conhecemos da arte, tecnologia e iconografia gregas do período.

Nossa pesquisa se filiou à metodologia de atribuição que tomou forma com os estudos específicos de John D. Beazley no início do século XX. Segundo essa metodologia, a observação minuciosa dos detalhes de uma obra, sejam estes formais, sejam decorativos, permite que traços específicos sejam reconhecidos e, finalmente, agrupados de maneira a oferecer a possibilidade de uma nomeação do artista produtor. As análises estilística e formal dos vasos aqui reunidos permitiram que sistematizássemos e corrigíssemos as atribuições publicadas ao longo dos anos, bem como contribuíram para que uma cronologia mais consistente fosse estabelecida. $\mathrm{O}$ estudo das imagens permitiu que conhecêssemos as especificidades de criação do Pintor de Gela, quais os temas abordados e que outras informações esses vasos poderiam nos fornecer, reforçando as atribuições finais de nossa pesquisa que serão aqui discutidas.

Para caracterizar a obra de nosso artista recorremos ao estudo aprofundado, sistemático e empírico do maior número possível de vasos atribuídos a ele, o que permitiu que compuséssemos um grande corpus documental, organizado nas formas de Catálogo de Vasos e de Banco de Dados Eletrônico. A principal referência bibliográfica de nossa pesquisa foi a obra Attic black-figured lekythoi (ABL) de 1936, em que C. H. E. Haspels, dedicando algumas páginas de seu livro a um conjunto de 214 vasos, definiu os traços e as características que a levaram a agrupálos e ligá-los formal e estilisticamente a uma personalidade artística a quem batizou 'Pintor de Gela'. Demais atribuições foram feitas posteriormente e divulgadas em publicações específicas, catálogos de coleções e revistas científicas ao longo dos anos, informações essas reunidas e disponibilizadas na Internet pelo Arquivo Beazley $(A B){ }^{1}$

Paralelamente aos levantamentos bibliográficos, foram feitas análises de aproximadamente uma centena de peças presentes em diversas coleções públicas na Europa e, ao fim de três estágios em museus, bibliotecas e outras instituições do exterior, pudemos reunir informações sobre 396 vasos ligados pela documentação ao Pintor de Gela, dos quais 242 puderam ser analisados empiricamente ou através da bibliografia. $^{2}$

Entretanto, observamos alguns problemas de ordem prática que acompanharam nossas pesquisas e que materializaram algumas questões para as atribuições dos vasos estudados. Primeiro, o acesso ao material: não foi tarefa das mais fáceis reunir um grande número de objetos; os vasos estão espalhados pelo mundo todo, o que tornou complexo, quando não impossível, o trabalho empírico. Nos casos de sucesso, quando pudemos trabalhar junto a museus e demais coleções, encontramos algumas outras dificulda-

(1) O Arquivo tornou-se uma ferramenta útil em nossa pesquisa por reunir diversas informações que indicam as coleções de origem e as publicações mais atualizadas sobre os vasos áticos, incluindo os atribuídos ao Pintor de Gela. Atualmente, o AB oferece entre 375 e 385 fichas dedicadas ao Pintor de Gela, mas nossa pesquisa demonstrou que algumas fichas estão duplicadas e algumas informações equivocadas. Sobre o surgimento do Arquivo, ver Robertson 1976.

Endereço eletrônico: www.beazley.ox.ac.uk

(2) Os demais 132 vasos compuseram uma Lista de Vasos não Incorporados ao Catálogo, uma vez que não foi possível reunir imagens ou maiores informações sobre eles. Os dados foram levantados no $A B$ e conhecemos apenas as atribuições indicadas nas fichas do Arquivo sem, no entanto, podermos confirmá-las ou corrigi-las. Esses vasos foram utilizados para a quantificação total das formas e dos conjuntos temáticos de vasos atribuíveis ao Pintor. 
des: o material pode ter sido deslocado, vendido, trocado, adquirido por outras instituições, o que fez com que algumas peças não fossem localizadas. Em alguns casos, os registros da peça foram por algum motivo alterados, mas não correspondidos nos documentos atuais, tornando-se comum o desaparecimento de peças dentro das próprias instituições.

A documentação bibliográfica também revelou alguns obstáculos: a irregularidade na disponibilização de dados em publicações, a insuficiência de boas imagens, a recorrência de informações conflitantes e por vezes equivocadas presentes na bibliografia geraram algumas questões que, de qualquer maneira, só puderam ser parcialmente respondidas através de análises sistemáticas do material reunido. Ainda sobre a bibliografia, foi preciso relevar algumas posições adotadas pelos estudiosos porque, de certa maneira, elas influenciaram algumas informações e resultados de análises que deveriam ser apenas de ordens prática e técnica, como observaremos ao longo deste artigo.

A pesquisa que permitiu a sistematização das atribuições apresentadas neste artigo materializou o problema das fontes. Foi somente através do estudo particular de cada peça para, inicialmente, caracterizar o Pintor e, consequentemente, atribuir, que pudemos, enfim, organizar os dados disponíveis, chegando a resultados que mudaram em parte as informações apresentadas no $A B L$, no $A B$ e em algumas outras publicações.

\section{Caracterização do artista denominado Pintor de Gela}

O Pintor de Gela possuiu uma longa carreira, iniciada aproximadamente na última década do século VI a.C.; estabelece-se um período de ao menos 35 anos para a produção dos vasos atribuídos a ele, com uma maior produção de vasos no $\mathrm{V}$ século. Hemelrijk (1974:118) indica uma cronologia mais absoluta para o início - entre 510-505 a.C. - e fim da produção, sendo que os últimos trabalhos podem ser datados por volta de 480-475 a.C.

Foi recorrente em nossa bibliografia de base - principalmente nos textos de Haspels e
Hemelrijk ${ }^{3}$ - encontrarmos junto às caracterizações de nosso artista comentários muito subjetivos com tendência a diminuir a sua obra, sobretudo no que se refere aos aspectos técnicos e estilísticos. O Pintor de Gela foi definido por Haspels ${ }^{4}$ como um artista menor que jamais alcançou além da mediocridade e que, no melhor dos casos, recusou-se a adaptar-se ao modo dominante. Suas obras "menos ruins" são, segundo a autora, também pouco originais, nas quais imita o trabalho de outros artistas. Seu estilo pessoal é qualificado de cômico e seus traços são entendidos como de origem provincial.

Ainda segundo Haspels, se houve um pintor responsável pela forma dos vasos, foi este: "há o mesmo espírito de desproporção em suas formas e em suas figuras pintadas; em seu período de declínio, quando seus vasos perdem todo o sentimento de proporção, o desenho cai no mesmo nível. Até mesmo em suas melhores produções, ele anda um pouco fora dos padrões. Suas figuras humanas são facilmente reconhecíveis: possuem longos narizes, pequenas pernas desajeitadas e sem emoção, com juntas inflexíveis[...]. Seus grupos nunca se tornaram unidades; ele não vai além de justaposições de figuras. Ele não é capaz de abstrair, de traduzir a realidade no estilo desse período" (ABL: 79).

Entretanto, temos uma opinião contrária: o Pintor não está preocupado com a estética apenas, ele possui preocupações técnicas em sua produção, o que faz com que se dedique a decorar seus vasos de acordo com o suporte, o que resulta por vezes em figuras desproporcionais, mas que acompanham a curvatura e o tamanho do vaso. Para Frontisi-Ducroux

(3) Apenas em 1974 foi publicado um trabalho exclusivamente dedicado ao Pintor de Gela: J. M. Hemelrijk (1974), em um artigo na revista BABesch, estudou os vasos da coleção do Museu Allard Pierson de Amsterdam, caracterizou o Pintor, fez correções e críticas às atribuições originais e acrescentou outros vasos à lista-base de Haspels.

(4) Haspels dedicou algumas páginas de seu $A B L$ ao Pintor de Gela: a caracterização desenvolvida no terceiro capítulo de sua obra, páginas 78-86, mais um Apêndice com os 214 vasos atribuídos ou ligados a ele (páginas 205-215, mais quatro pranchas com imagens de 15 vasos de sua lista). 
DIAS, C.K.B. Apontamentos sobre a atribuição de vasos áticos: a produção do Pintor de Gela. Revista do Museu de Arqueologia e Etnologia, São Paulo, 19: 235-255, 2009.

(1996:193), o Pintor de Gela "sabe construir uma imagem” e não é desprovido de capacidade de abstração ou conhecimentos artísticos como Haspels demonstra em sua obra.

O Pintor ainda utiliza técnicas originais se não quase inexistentes, ao menos pouco utilizadas na Ática, como o agrupamento vertical das imagens para dar uma idéia de espaço e movimentos circulares, o que vai contra a idéia de Haspels de que "suas figuras não formam uma unidade, apenas se justapõem”. Observamos essa técnica em vasos como a enócoa de Munique, Antikensammlungen $1824^{5}$ (Figura 6 - pormenor), em que quatro bois circundam um altar, orientados da esquerda para a direita - o animal que passa atrás é representado como se estivesse sobre o altar mas, como seus cascos não aparecem, tem-se a idéia de profundidade; na enócoa de Amsterdam, Mus. Allard Pierson 3742, ${ }^{6} \mathrm{em}$ que Sátiros pulam, passam por baixo de uma mesa, pisoteiam uvas, e na olpa de Paris, Museu do Louvre F334, ${ }^{7}$ em que Sátiros e Mênades se penduram em uma árvore para colher frutos. $\mathrm{O}$ artista representa as personagens em diversos tamanhos e em diferentes posições, dando movimento e profundidade à cena, apresentando um realismo não encontrado frequentemente nos vasos de figuras negras do mesmo período.

Como características principais dos vasos atribuídos ao Pintor de Gela, observamos a argila que é propriamente grosseira e o verniz negro que possui um brilho metálico que tende ao verde. Quanto às formas, seus vasos possuem diferentes dimensões: $\mathrm{o}$ artista tanto produz vasos pequenos, alguns quase miniaturas, quanto vasos de grandes proporções. Fazem parte de seu repertório os

(5) Enócoa de Munique, Antikensammlungen 1824, encontrada em Vulci, Itália, atribuída ao Pintor de Gela por Haspels, datada de 500 a.C. ABL 214.185; $\mathrm{ABV}$ 473, 185; CVA Munique 12, beilage 1, prs. 48.14, 49.1-4

(6) Enócoa de Amsterdam, Allard Pierson Museum 3742, proveniência desconhecida, atribuída ao Pintor de Gela por Hemelrijk, datada de 500 a.C. BABesch 49, 1974:125, figs. 1, 19-25

(7) Olpa de Paris, Museu do Louvre F 334, encontrada em Cápua, Itália, atribuída ao Pintor de Gela por Beazley, datada de 500-490 a.C. ABL 215.203; ABV 473.203, BABesch 1974:155, fig. 68 . lécitos (Figura $1^{8}$ ), principal forma produzida pelo artista e, em menor quantidade, as enócoas (Figura 2), as olpas (Figura 3) e as ânforas (Figura 4).

Como outros pintores de seu tempo (Boardman 1991), o Pintor de Gela produz lécitos cilíndricos, mas seus vasos são um pouco mais espessos e com forma mais bojuda. Inicialmente, ele utiliza o sistema convencional de sete palmetas na decoração dos ombros, mas posteriormente muda para sistemas de cinco palmetas e dois botões, ou três palmetas e dois botões, entre outras pequenas alterações. Esse sistema decorativo formado por palmetas abertas e botões de flores é o elemento principal na decoração do ombro de todos os lécitos atribuídos ao Pintor de Gela. As palmetas não são estilizadas, Haspels diz que "elas são plantas vivas desabrochando, com grandes botões saindo dos caules e acompanhados de pequenas folhagens" (1936:79) e, de tão características, estabeleceram-se como a principal assinatura do Pintor. As palmetas estão presentes em quase todos os vasos atribuídos ao Pintor de Gela, e aparecem organizadas em diversos tipos de arranjos na decoração do ombro de todos os seus lécitos (Figura $5^{9}$ ), ou em faixas e detalhes decorativos nas outras formas de vasos atribuídos a ele.

(8) Todos os desenhos foram feitos a partir de fotografias e informações das dimensões (altura e diâmetro) por Gilberto da Silva Francisco (2009). (9) Todas as fotografias presentes neste artigo fazem parte de um arquivo pessoal formado durante as etapas de análise do material publicado presente em museus e instituições na Europa durante os anos de 2004, 2006 e 2008. Agradecemos a colaboração das seguintes instituições: Escola Americana e Museu da Ágora, Atenas; Museu Nacional de Atenas; Escola Alemã e Museu do Cerâmico, Atenas; Museu Kanellópoulos, Atenas; Escola Americana e Museu Nacional de Corinto; Museu Nacional Etrusco de Villa Giulia, Roma; Museu Arqueológico Nacional de Nápoles; Museu Arqueológico Nacional de Tarento; Museu Arqueológico Nacional de Agrigento; Museu Arqueológico Nacional Paolo Orsi, Siracusa; Museu Arqueológico Regional Antonio Salinas, de Palermo; Museu Arqueológico de Gela; Museu do Louvre, Paris; Cabinet des Medailles, Biblioteca Nacional de Paris; Museu Ha'Aretz, Tel Aviv. Créditos das imagens: Carolina Kesser Barcellos Dias; Fig. 10b: CVA Munique 12, beilage 1, prs. 48.1-4, 49.1-4; Fig. 11: BABesch 49, figs. 1, 19-25. 


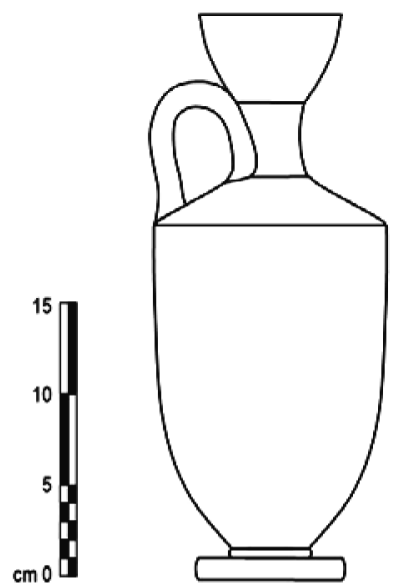

Londres, M. Britânico 1772.3-20.2

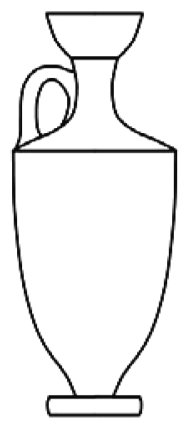

Delos, Mus. Arq. 6.128

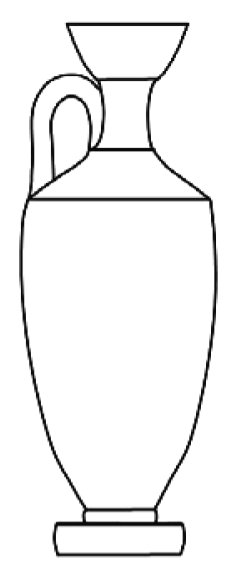

Siracusa, Paolo Orsi 21941

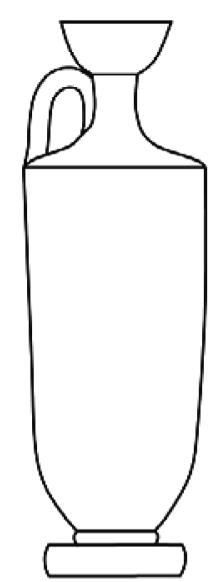

Siracusa, Paolo Orsi 19884

Fig. 1. Variações de formas dos lécitos atribuídos ao Pintor de Gela.

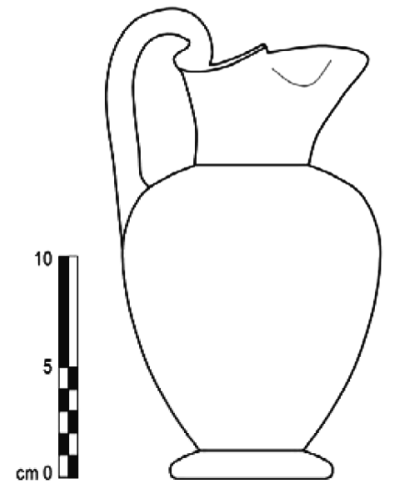

Munique, Antikesammlungen 1824

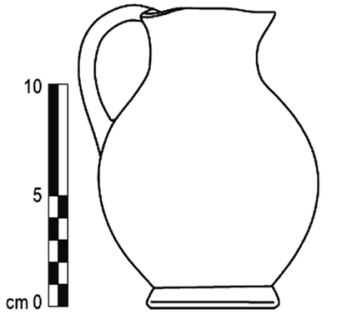

Leiden, Rijksmuseum K.94/9.20

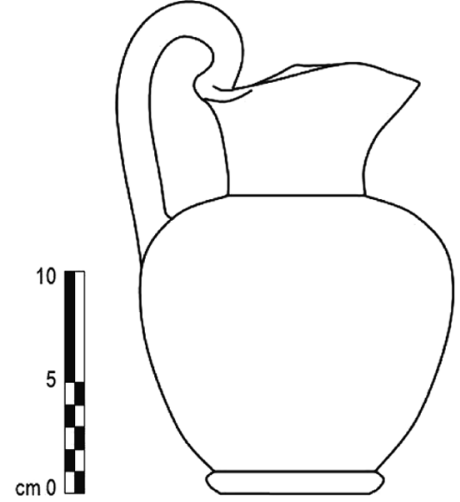

Amsterdam, APM 3742

Fig. 2. Variações de formas das enócoas atribuídas ao Pintor de Gela.

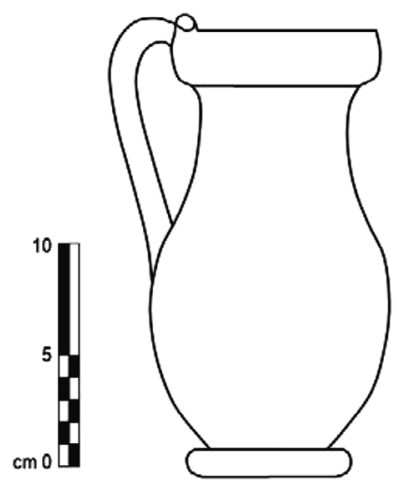

Roma, Mus. de Villa Giulia 20915 Paris, Museu do Louvre F 333

Fig. 3. Tipos de olpas atribuídas ao Pintor de Gela.

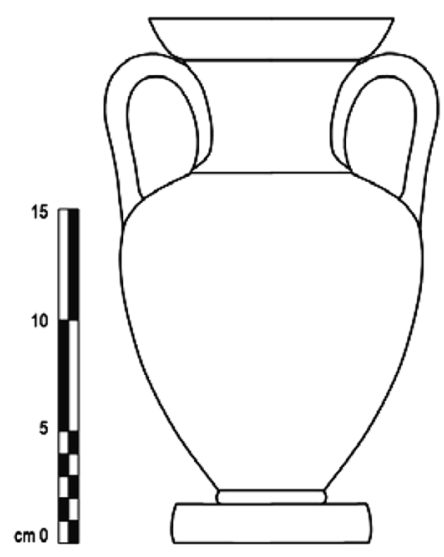

Palermo, Mus. Regional NI 1955

Fig. 4. Ânfora atribuída ao Pintor de Gela. 

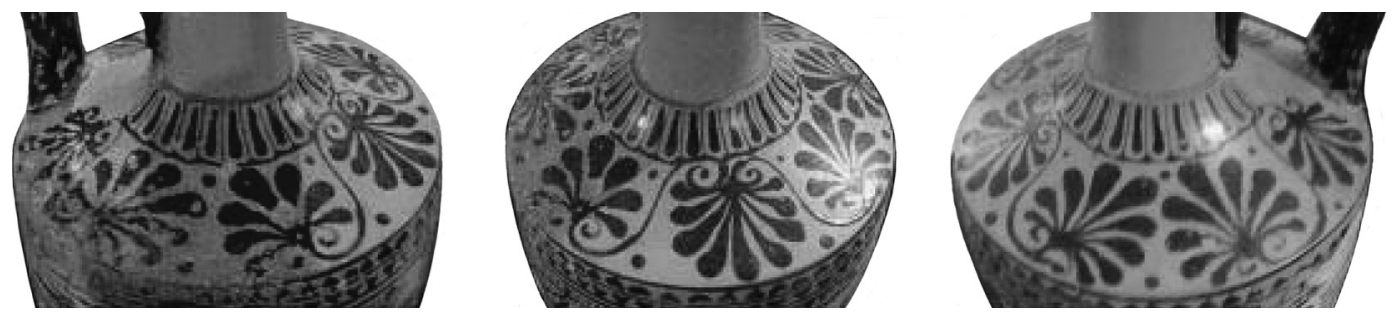

Agrigento, Mus. Arq. Regional R 145
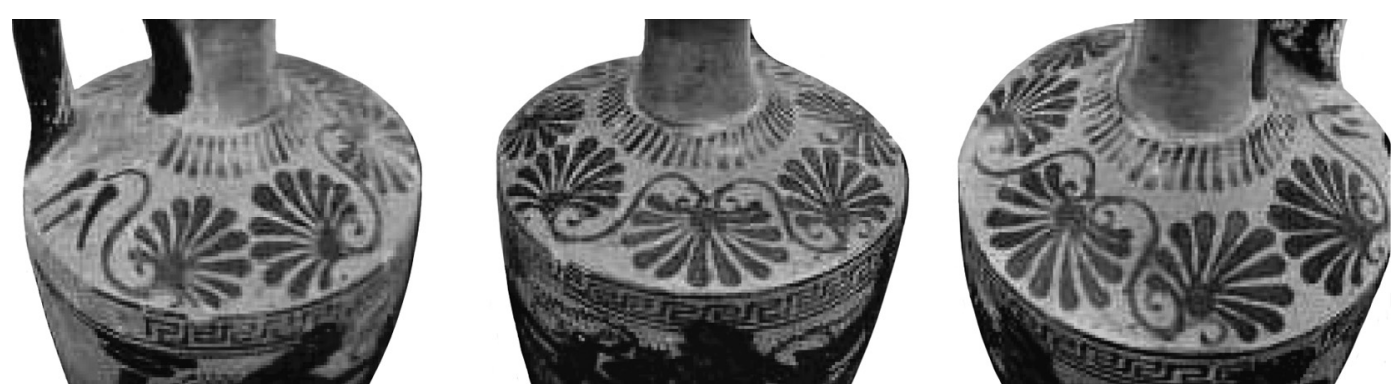

Paris, Cabinet des Medailles 284
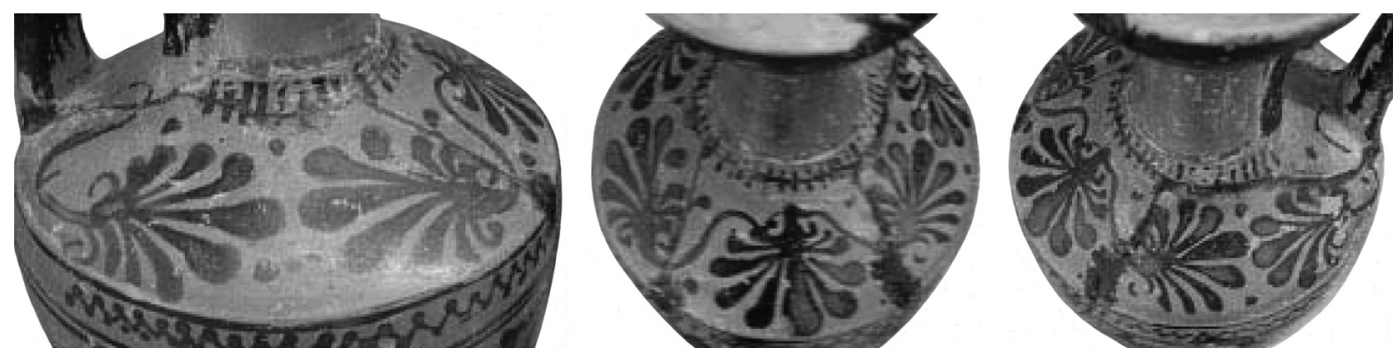

Palermo, Museu Arq. Regional Antonio Salinas NI 1892
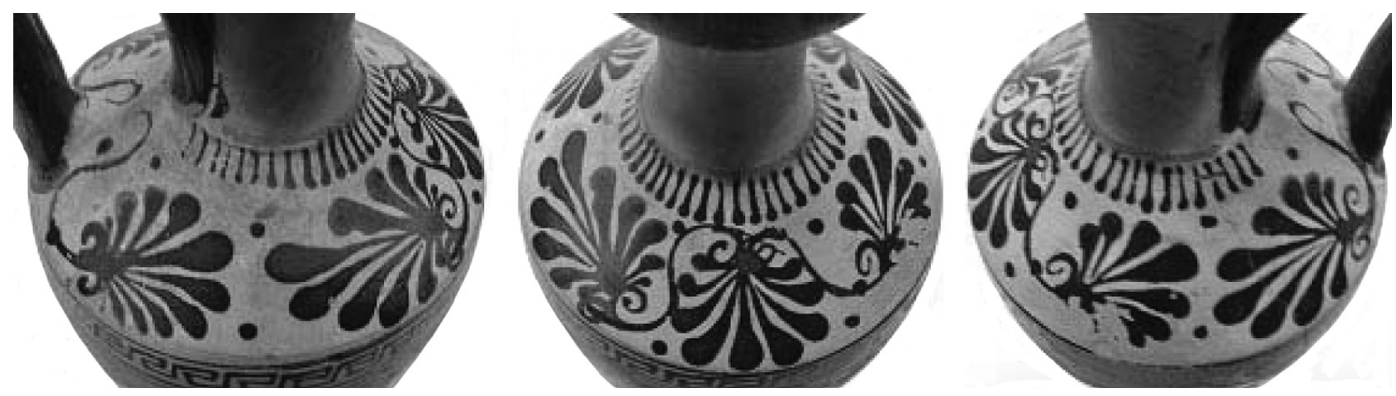

Siracusa, Museu Arq. Nacional Paolo Orsi 21941

Fig. 5. Sistemas de Palmetas em lécitos atribuídos ao Pintor de Gela. (Fotografias: Carolina Kesser Barcellos Dias). 

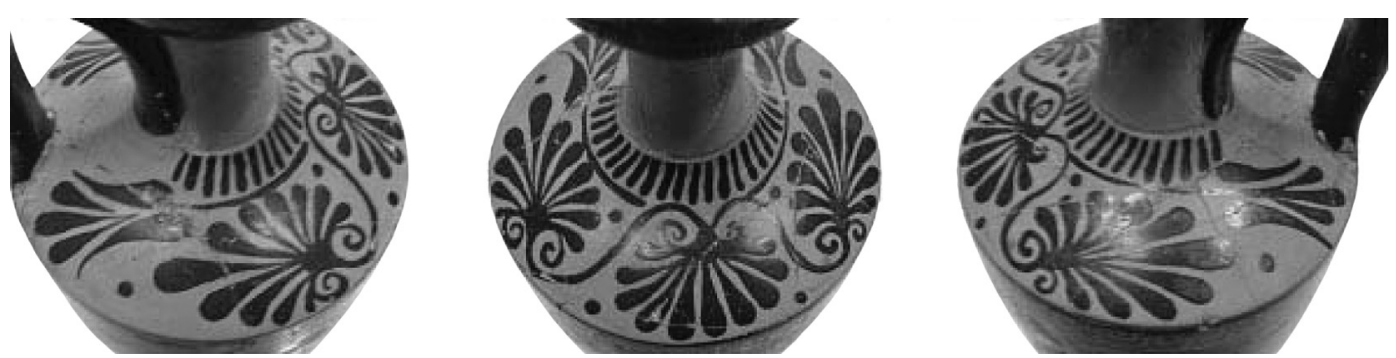

Siracusa, Museu Arq. Nacional Paolo Orsi 26750
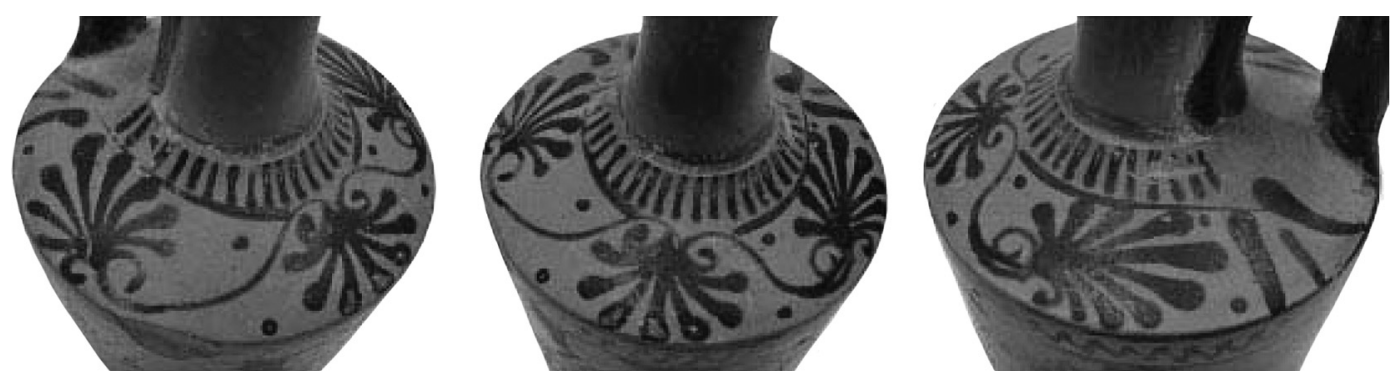

Siracusa, Museu Arq. Nacional Paolo Orsi 19857
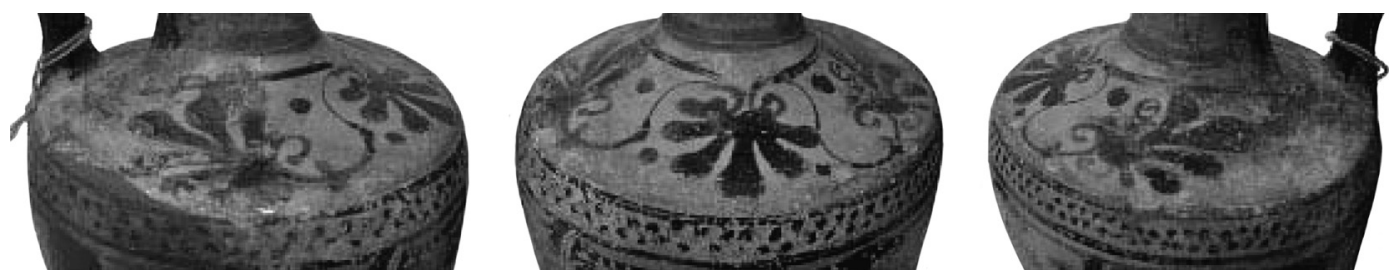

Paris, Museu do Louvre F 435
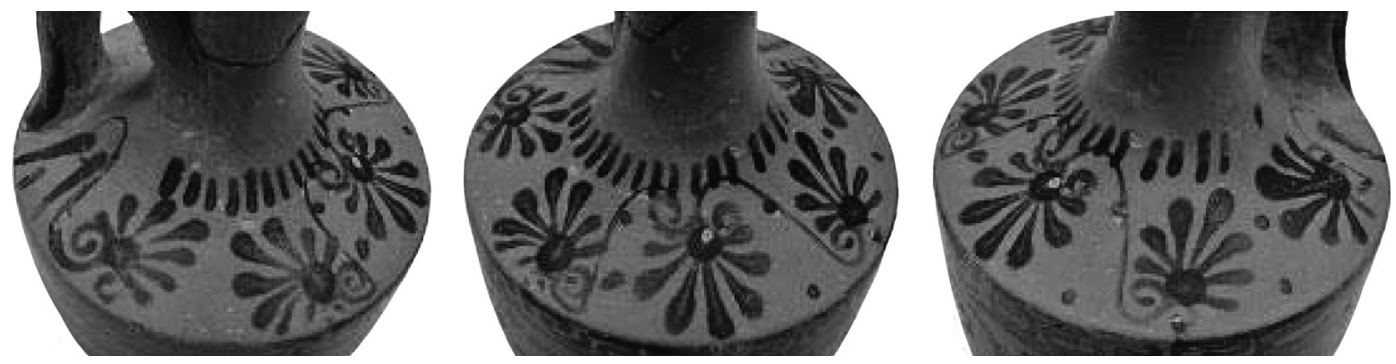

Siracusa, Museu Arq. Nacional Paolo Orsi 19823

Fig. 5. Sistemas de Palmetas em lécitos atribuídos ao Pintor de Gela. (Fotografias: Carolina Kesser Barcellos Dias). 
DIAS, C.K.B. Apontamentos sobre a atribuição de vasos áticos: a produção do Pintor de Gela. Revista do Museu de Arqueologia e Etnologia, São Paulo, 19: 235-255, 2009.

Nos lécitos (Figura 6a-e), além do sistema de palmetas (Figura 6b), outros elementos decorativos contribuem para a caracterização de seu estilo: na base do pescoço dos lécitos, há normalmente uma faixa de linguetas (Figura 6a) - acompanhada em sua maioria por uma linha vermelha imediatamente acima do ombro; algumas vezes as linguetas se aproximam muito ou até se apoiam nas volutas das palmetas. Sobre o campo figurado há uma faixa decorativa, normalmente delimitada acima por uma linha horizontal e abaixo por duas. Há uma grande variedade de tipos das faixas decorativas, sendo aquela formada por pontos ligados em zigzag (Figura 6c) a mais comum. Uma linha horizontal (Figura 6d) delimita a parte inferior do campo figurado, como se compusesse os limites do solo, embora algumas vezes os membros inferiores de personagens, rodas de carros, entre outros, a ultrapassem. Finalmente, a boca, a alça e a parte inferior do vaso (Figura 6e) são cobertas por verniz negro.

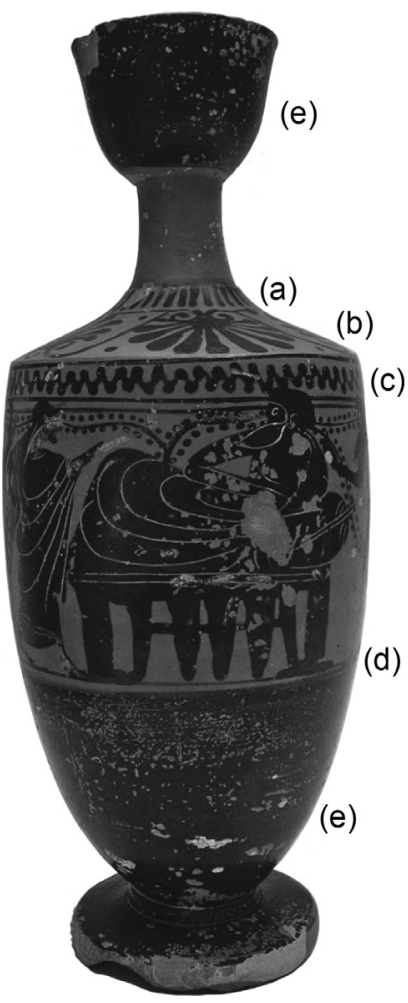

Fig. 6. Lécito, Siracusa, Museu Arq. Paolo Orsi 14565, atribuído ao Pintor de Gela por Haspels (Fotografia: Carolina Kesser Barcellos Dias).
O fundo das cenas normalmente é decorado com galhos estilizados, frutos - pequenos pontos negros e bolas pintadas de branco e/ou grandes cachos de uvas negros estilizados, ou algum outro tipo de vegetação, como pequenas árvores e palmeiras. A adição de cores é muito comum nos vasos atribuídos ao Pintor de Gela: o branco é adicionado para detalhes da decoração, normalmente frutos, tecidos, detalhes nas vestimentas das personagens, na anatomia dos animais e, como de praxe, na pele das figuras femininas. O vermelho, que pode adquirir uma tonalidade forte e alaranjada ou mais escura e púrpura, aparece frequentemente nas linhas horizontais que decoram a base do pescoço, em algumas linhas horizontais que compõem as faixas decorativas, e comumente em barbas, cabelos, fitas, caudas de Sátiros e de animais, arreios, detalhes de carros, detalhes nas vestimentas e em linhas horizontais no limite inferior da cena, próximas à área negra reservada ao final do vaso.

Ocorre em alguns vasos atribuídos ao Pintor de Gela o uso de letras no fundo da cena $(\mathrm{NO}, \mathrm{NN}, \mathrm{NE}, \mathrm{NON}$, entre outros arranjos). Essas letras possuem caráter decorativo, uma vez que não formam palavras e vêm desprovidas de significado, mas podem ser interpretadas como tentativas de sonorização da imagem, como sugere Frontisi-Ducroux (1996:198), criando uma expressão gráfica do movimento e agitação que envolvem certas narrativas, como em algumas cenas na palestra, cenas com instrumentos musicais, cenas de caça ou cenas dionisíacas, por exemplo.

Alguns vasos possuem grafite no pé, mas essas marcas não apresentam consistência que possa fornecer algum dado sobre marca da oficina; são riscos aleatórios, que se parecem com letras, mas sem significado definido.

As figuras humanas (Figura 7a-e) são facilmente reconhecíveis: elas possuem nariz longo, olhos arredondados, com a pupila e o globo ocular bem definidos e boca marcada por pequenas incisões. Nas figuras masculinas, a barba é simples e rígida, normalmente desenhada em uma única linha desde a testa, passando pela orelha; raras vezes as figuras 


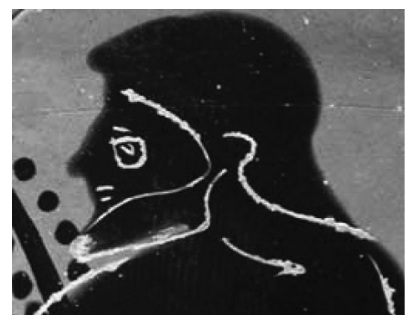

Siracusa 19884

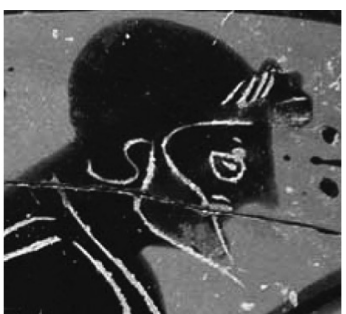

Siracusa 19884

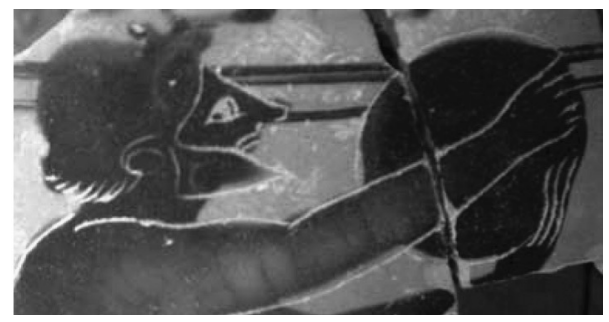

Agora P 24538

Fig. 7 a. Detalhes de rostos masculinos.

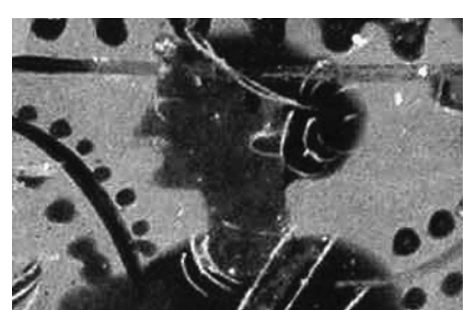

Siracusa 19857

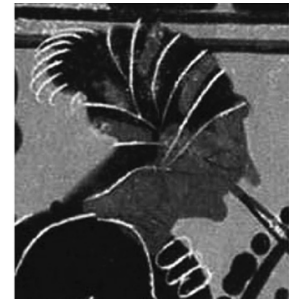

Siracusa 26750

Fig. 7 b. Detalhes de rostos femininos.

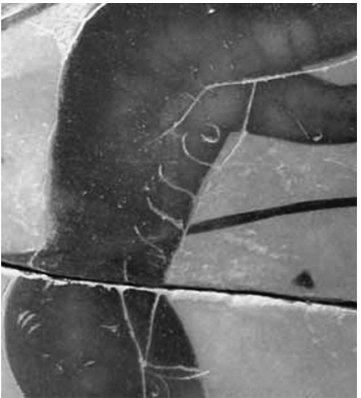

Agora P 24538

Fig. 7 c. Detalhes musculatura.

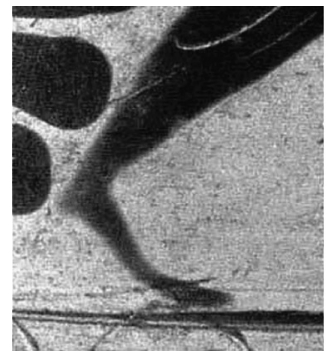

Louvre F162

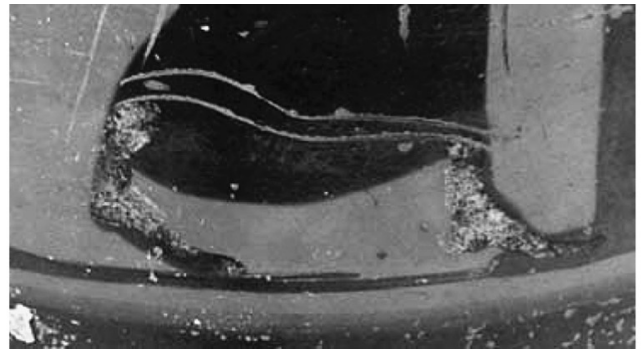

Siracusa 14565

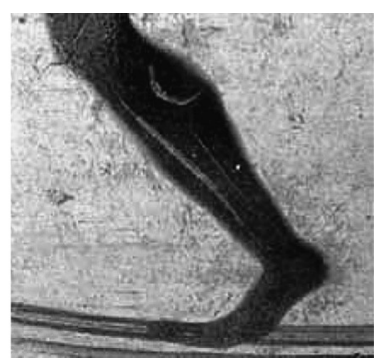

Louvre F162

Fig. 7 d. Detalhes pernas e pés.

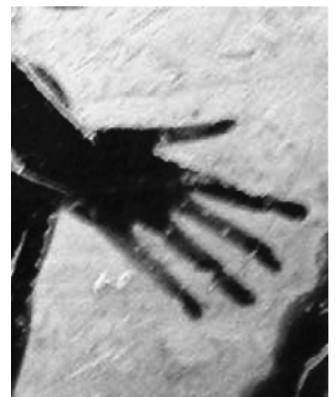

Palermo 2023

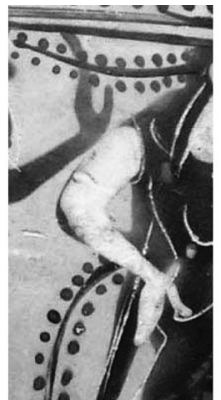

Londres MB 63.7-28.224

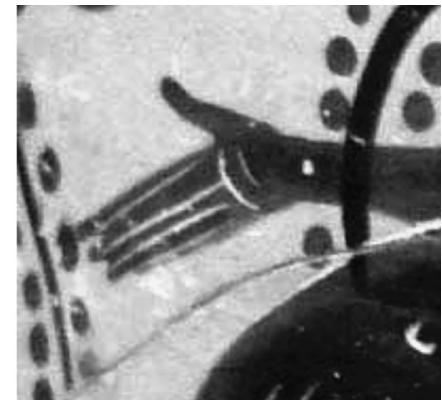

Atenas MN 18568

Fig. 7 e. Detalhes das mãos. 
DIAS, C.K.B. Apontamentos sobre a atribuição de vasos áticos: a produção do Pintor de Gela. Revista do Museu de Arqueologia e Etnologia, São Paulo, 19: 235-255, 2009.

masculinas são imberbes. Os cabelos variam de longo, sobre os ombros, ou curtos e bem definidos por incisões (Figura 7a). Nas figuras femininas é mais difícil perceber detalhamento do rosto, sobretudo porque o branco sobre o verniz negro não se preservou muito bem e as incisões são muito fracas. Nas figuras em que ainda é possível discernir o rosto, o tratamento é basicamente o mesmo: nariz longo, olhos amendoados marcados por incisões muito leves e quase desaparecidas; a boca é imperceptível na maioria. Os cabelos são normalmente presos em coque e é comum que tenham fitas, faixas ou tiaras na cabeça (Figura 7b).

Os troncos das figuras masculinas (Figura 7c) possuem poucas incisões para marcar a musculatura do abdome e peitoral; são poucas e fortes linhas que definem o corpo. O sexo é marcado por duas incisões contínuas, mesmo nos Sátiros que não possuem falo pronunciado. As pernas masculinas são curtas, rígidas, e, algumas vezes, desproporcionais. A musculatura é marcada por incisões fortes, sem muito detalhamento: normalmente uma linha curva e uma linha reta marca a panturrilha; os pés também são simples, e raramente há definição dos dedos (Figura 7d).

Os braços masculinos são simples e fortes, mas não é comum que a musculatura esteja marcada; normalmente há uma linha incisa contínua que marca o ombro e o braço. Quando os braços estão dobrados, os cotovelos são simples e não possuem incisões para marcar o osso, há apenas a linha de contorno do braço. As mãos são particularmente simples mesmo quando há um maior detalhamento dos dedos (Figura 7e). Sobretudo mãos de Sátiros e Mênades são exageradamente simplificadas, parecendo folhas.

As figuras animais (Figura 8) recebem o mesmo tratamento dado às figuras humanas: incisões fortes para marcar detalhes da anatomia e adição de cores para alguns detalhes; são comuns os touros, carneiros, cavalos, burros, cervos, cães e pássaros.

Elementos arquitetônicos e delimitadores de espaço são comuns: há uma predileção por colunas do tipo dórico (Figura 9) que podem indicar espaço sagrado, estruturar fontes, ou delimitar espaços fechados em que amantes ou músicos se encontram. Os altares são construções baixas, com volutas e frisos e o fogo sempre indicado (Figura 10a). Há um outro tipo de altar grande, sólido e sem decoração, que delimita o espaço de grandes touros em cenas de contexto sacrificial (Figura 10b). Em outras cenas com touros, o lutério (Figura 11) aparece no lugar do altar e consiste de uma grande bacia equilibrada em um pedestal sólido, por vezes acompanhada por colunas e vegetais. São comuns as mesas (Figura 12) e klinai, elementos simples, às vezes com pequenos detalhes decorativos, como volutas e adição de cor branca.

Paredes grossas e pedregosas (Figura 13) são utilizadas para indicar espaços fechados, como cavernas, sobretudo nas cenas que retratam a fuga de Odisseu e seus companheiros da caverna de Polifemo, ou o encontro de Centauros em frente ao pito.

Esses elementos também servem para, além de marcar os espaços, reforçar a simetria, contribuir para o movimento das personagens e criar segundos planos nas cenas.

Quanto aos temas decorativos de seus vasos (Gráfico 1), há uma grande repetição de cenas, com algumas poucas alterações no gestual: o universo dionisíaco é o tema com maior número de representações; o ciclo de Héracles aparece em seguida na ordem de preferência sendo a luta pelo trípode, um episódio importante na mitologia de Héracles, um dos temas recorrentes. Cenas com a presença de demais divindades são menos comuns, mas quando ocorrem, apresentam sobretudo Atena, Ártemis, Apolo, Hélio e Hermes; outros heróis aparecem poucas vezes: Odisseu em três lécitos, Peleu em dois e Teseu em apenas um. Cenas sacrificiais em que animais - touros ou carneiros - aparecem próximos a altares ou aos lutérios fazem parte do conjunto temático presente nos vasos, assim como cenas de armamento, cavaleiros e caçadores, cenas de palestra e cenas de intimidade ou do núcleo doméstico.

No geral, o estilo do Pintor de Gela é muito característico, permitindo que as atribuições feitas até hoje estejam, de maneira geral, corretas. 


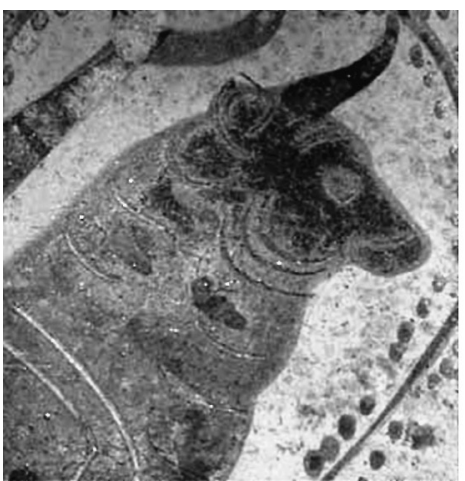

Paris, Museu do Louvre F 333

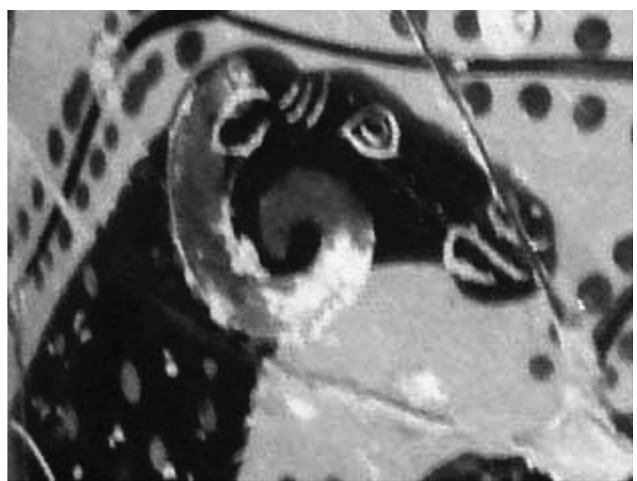

Atenas, Museu Nacional 18568

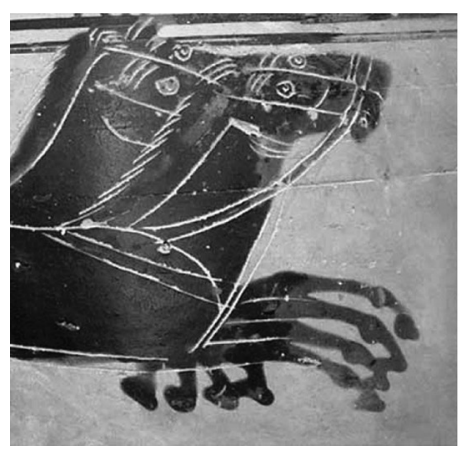

Londres, Mus. Britânico 1836.2-24.129

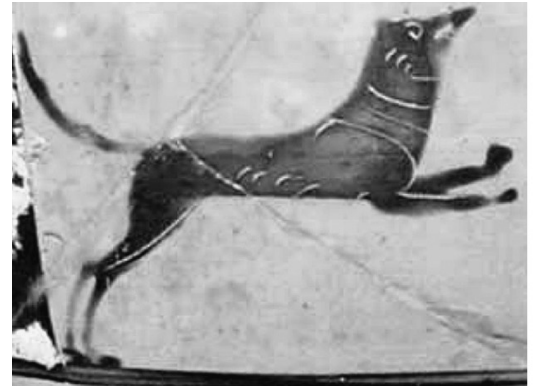

Londres, Museu Britânico 543

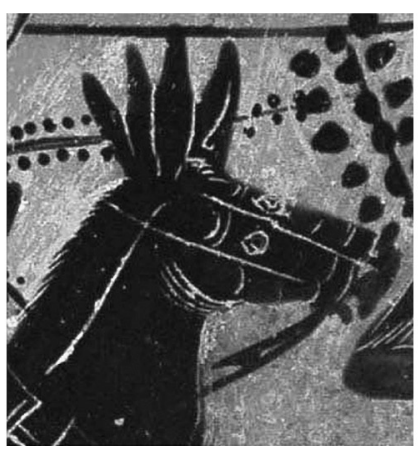

Siracusa, Paolo Orsi 19881

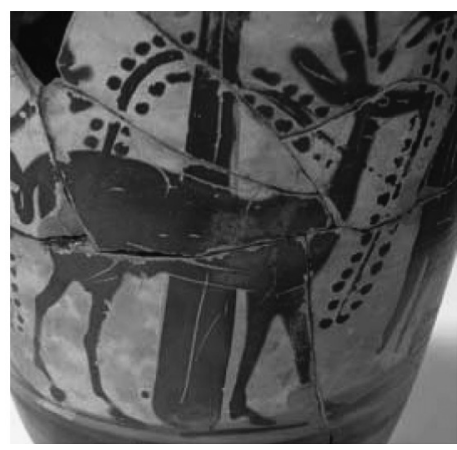

Atenas, Museu da Agora P 2569

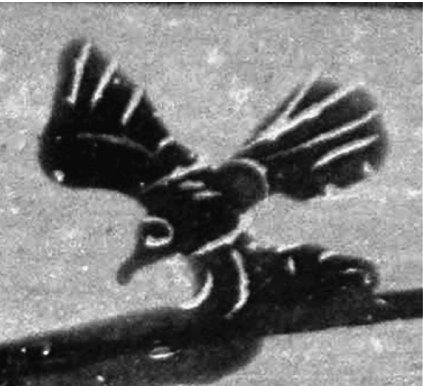

Siracusa, Paolo Orsi 21139

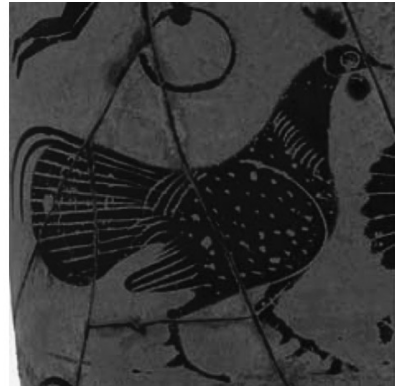

Siracusa, Paolo Orsi 19854

Fig. 8. Animais comumente presentes no repertório temático dos vasos atribuídos ao Pintor de Gela (Imagens: Carolina Kesser Barcellos Dias).

Os elementos estilísticos, traços e detalhes anatômicos das figuras devem ser observados em conjunto com as informações formais e decorativas para que possamos entender e confirmar as atribuições ao Pintor de Gela. Portanto, do total de 242 vasos estudados, confirmamos 176 atribuições ao Pintor de Gela.
Porém, há um conjunto de vasos atribuídos não ao Pintor mas próximo a ele e que podem ter sido fabricados por discípulos ou outros artistas em um mesmo ateliê. No ABL, Haspels separara 11 peças em dois grupos principais que poderiam ser ligados ao Pintor, mas que possuíam características decorativas específicas. No 


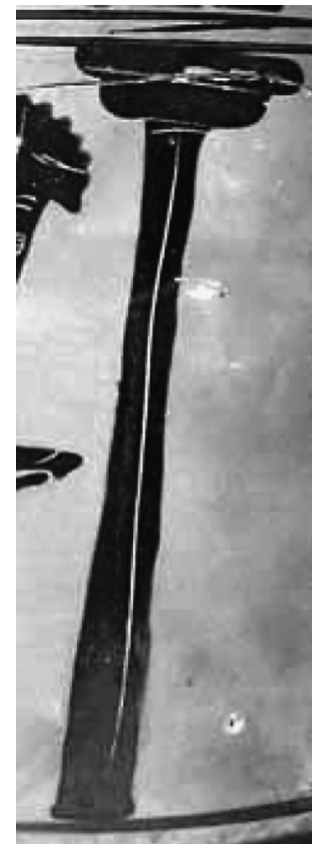

Atenas, Museu da Agora P 24105

Fig. 9. Coluna.
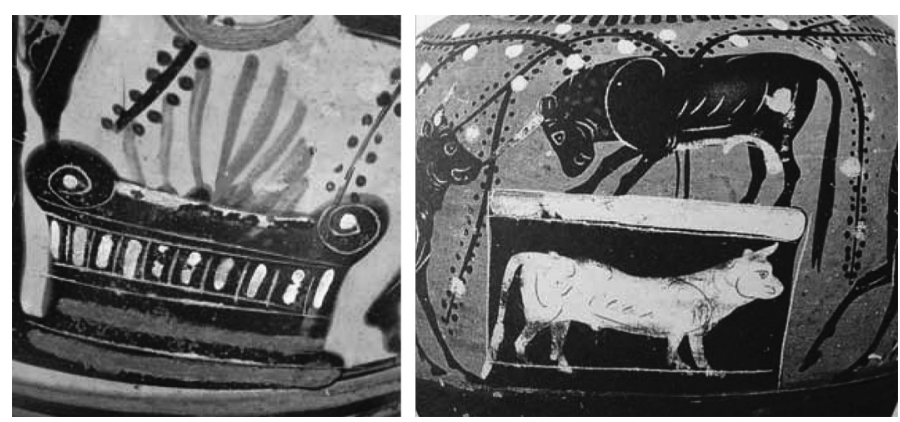

Paris, Cabinet des Medailles 284 Munique, Antikensammlungen 1824

Fig. 10 (a, b). Tipos de altares.

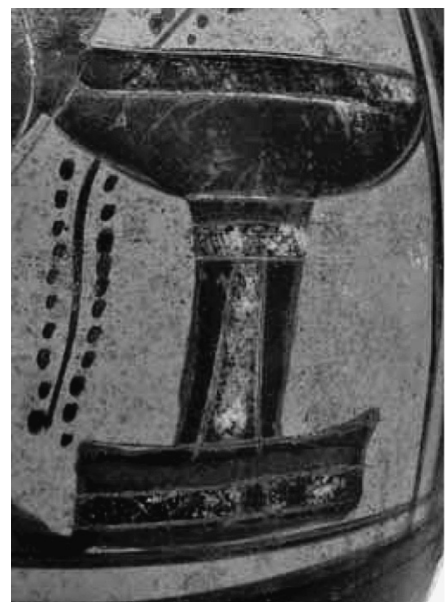

Paris, Museu do Louvre F 333

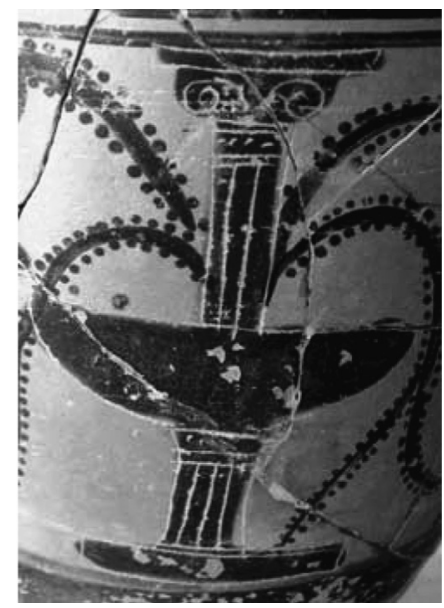

Atenas, Museu Kanellopoulos 79

Fig. 11. Tipos de loutérios presentes em cenas sacrificiais.

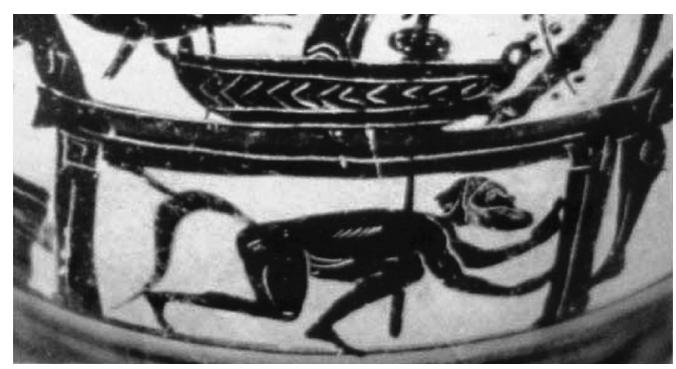

Amsterdam, Allard Pierson Museum 3742

Fig. 12. Tipo de mesa comum.

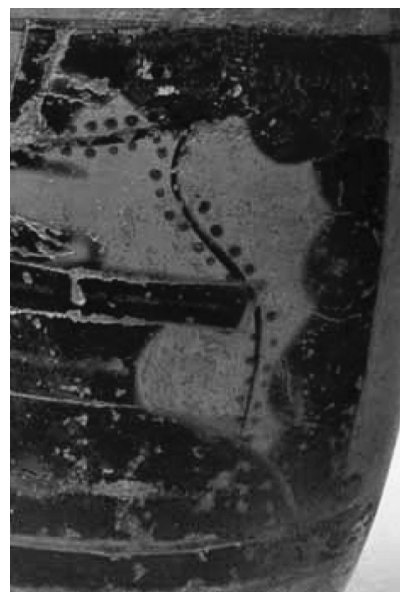

Paris, Museu do Louvre F435

Fig. 13. Estrutura rochosa. 


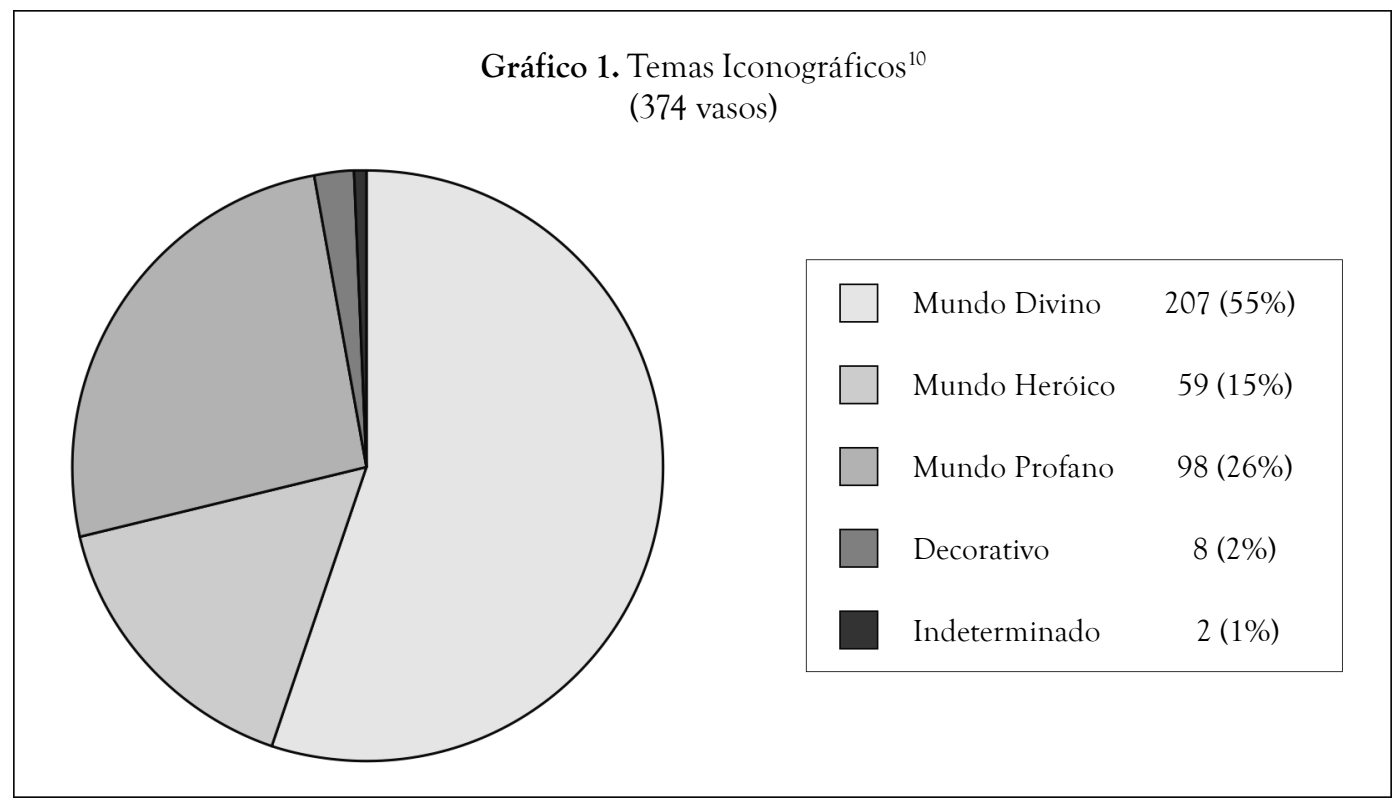

restante de nossa documentação encontramos outros vasos atribuídos de diversas maneiras: "near Gela Painter" ou "manner of Gela Painter", entre outros termos menos recorrentes, porém mais questionáveis, como "connected to", "to compare with”, “maybe...”, "Gela Painter?”.

Reduzimos essa gama de termos a duas principais formas - à maneira do Pintor de Gela e à oficina do Pintor de Gela - de acordo com uma proposta de atribuição baseada em critérios específicos. Acreditamos que com essas propostas visualizamos não só as características próprias do Pintor, mas também destacamos do conjunto

(10) Para o estudo iconográfico, organizamos as imagens de acordo com as personagens consideradas principais em cena, refinando a organização temática através da análise do gestual, do tipo de ação, sempre começando pela cena mais complexa e chegando à mais reduzida, definindo as cenas e agrupando-as. As imagens foram abordadas em sequências pertencentes a duas esferas generalizantes, a 'Mitológica' e a

'Humana' e, então, organizadas em sub-temas específicos de imagens dos mundos 'divino', 'heróico' e 'humano'. Por 'mitológicas' entendemos toda e qualquer cena que envolva a presença de pessoas mitológicas reconhecidas por atributos e por recorrência iconográfica. Os vasos com imagens interpretadas dessa maneira foram reunidos nos grupos "Imagens do Mundo Divino: Divindades e Episódios Divinos" e "Imagens do exemplos para os quais outras mãos fossem correspondidas, o que nos permitiu responder algumas questões sobre a colaboração de artistas nas produções.

Para aquelas atribuições questionáveis devidas à impossibilidade de observação dos elementos básicos em conjunto ou por ausência de elementos indispensáveis para a atribuição, especificidades de forma, decoração, traços, ou qualquer outro questionamento de ordem prática ou metodológica, propusemos uma análise que resultou na sistematização de atribuições e estabeleceu quais os vasos que não

Mundo Heróico: Heróis e Episódios Heróicos”; neste gráfico, consideramos as 171 cenas com presença de personagens mitológicas, acrescentando ao total as 36 cenas interpretadas como Sacrificiais - 23 das quais com presença de figuras míticas. Por 'humanas' consideramos todas as cenas narrativas em que figuras entendidas como humanas - atletas, artesãos,

cavaleiros, entre outros - participem de atividades em que não exista a presença física de personagens míticas e que, portanto, foram reunidas no grupo "Imagens do Mundo Profano". Há também um pequeno conjunto de vasos decorados apenas com florais ou padrões geométricos e fragmentos cuja personagem é indeterminada, agrupados no conjunto denominado "Padrões decorativos e figuras indeterminadas". 
DIAS, C.K.B. Apontamentos sobre a atribuição de vasos áticos: a produção do Pintor de Gela. Revista do Museu de Arqueologia e Etnologia, São Paulo, 19: 235-255, 2009.

poderiam ser atribuídos ao Pintor de Gela e sim à sua maneira ou à sua oficina ou, finalmente, excluídos do conjunto.

\section{Sistematização das atribuições ao Pintor de Gela}

Após as primeiras atribuições de Haspels no $A B L$, muitas outras peças foram incluídas no conjunto de vasos atribuíveis ao Pintor ou ao seu meio, publicados por diversos autores ao longo dos anos, em diversos tipos de publicações. Mas alguns de nossos questionamentos sobre as atribuições de vasos ao Pintor de Gela se iniciaram ao observarmos a lógica interna das atribuições de Haspels e da própria apresentação do material em seu livro, que peca pela insuficiência de imagens.

As peças separadas no ABL foram ligadas ao Pintor ("Lekythoi connected with the Gela Painter", pp. 86 ; 215) pois a autora as considerou próximas em estilo aos demais vasos do conjunto. Entretanto, além dessas 11 peças, a autora marcou 53 outros vasos que apresentavam pequenas variações na forma, na decoração ou na aparência das figuras, considerando-os produtos de "baixa produção do Pintor de Gela", sugerindo, inclusive, que esses vasos tenham sido obras de "pupilos".

Entendemos que esses vasos tenham sido marcados por possuírem características do que Haspels considera 'produção em massa', já que as formas - que a autora não considera tão perfeitas - e os temas se mantêm. Mas, diferentemente do que parece sugerir Haspels, eles não nos pareceram 'descuidados' ou 'feitos apressadamente', numa livre tradução do termo utilizado pela autora, ${ }^{11}$ sobretudo no que diz respeito às formas. Entendemos que Haspels julgou os vasos principalmente sob o ponto de vista estilístico dos traços das personagens sem insistir muito no conjunto de informações, ou seja, observando também o sistema de palmetas e as faixas decorativas.

(11) "A large number of vases are on a level far below his other productions. They have the look of hasty mass-products" (Haspels 1936:85-6).
Também não concordarmos com outra afirmativa da autora de que as formas desses 'vasos inferiores' fossem mal proporcionadas ou ruins, ${ }^{12}$ mesmo porque muitos outros lécitos atribuídos ao Pintor pela própria Haspels possuem exatamente a mesma forma. A não ser que o problema esteja na suposta aparência de produção em massa, as formas não são despadronizadas ou diferentes da maioria dos vasos atribuídos ao Pintor. Contudo, apesar de marcados, esses 53 vasos permaneceram no conjunto de vasos atribuídos ao próprio Pintor, independentemente, enfim, dos questionamentos da autora sobre a aparência, forma, tema iconográfico e decoração.

O problema das atribuições questionáveis aumentou quando, ao longo dos anos, peças com características similares ou completamente diversas - sejam elas estilísticas, formais ou decorativas - passaram a ser conhecidas e atribuídas ao Pintor de Gela não mais por Haspels, mas por outros estudiosos.

A diferença de abordagem, a compreensão ou não de quais traços e características deveriam ser levados em conta, a análise do material - os vasos ou seus registros fotográficos - entre outras situações, conduziram as inúmeras novas atribuições ao Pintor de Gela, à sua maneira, à sua oficina, entre outras terminologias. Isso resultou em um grande número de peças com atribuição questionável, alterações nos dados sobre o artista e seu meio e, enfim, uma série de informações equivocadas que podem comprometer os estudos relativos à produção cerâmica de maneira global.

Ora, segundo a metodologia da atribuição, são os traços estilísticos que podem caracterizar uma personalidade artística. A observação desses traços em conjunto com as formas, decoração acessória e a técnica, é o que fornecerá dados mais completos para a caracterização de artistas e as possiveis nomeações, filiações e agrupamentos.

Porém, a experiência empírica é fundamental. É muito mais simples compreender o que quer dizer "observar os traços, estilo, técnica e

(12) "The shapes of these inferior vases are shockingly bad and ill-proportioned - as far below his ordinary level as the painting is" (Haspels 1936:85-6). 
formas particulares de cada artista" quando se tem uma peça disponível, quando se pode depois estabelecer relações entre essa peça e outras e, finalmente, quando é possível observá-las em conjunto. Beazley disse isso, ${ }^{13}$ a metodologia da atribuição ensina isso, nós procuramos fazer isso. Mas não podemos esperar que todos os autores tivessem as mesmas oportunidades ou que apresentassem os mesmos objetivos. Listar, explicar ou apenas escrever sobre traços que preferencialmente deveriam ser vistos para que se tenha a compreensão exata do que se trata 'atribuir' é uma tarefa complexa e cheia de falhas.

Portanto, procuramos primeiro observar as características que determinaram a atribuição dos vasos ao denominado "Pintor de Gela" no ABL. Em seguida, procuramos refinar essa caracterização feita por Haspels e apresentar os elementos que possibilitaram a sistematização das demais atribuições feitas por ela e posteriormente encontradas em nosso levantamento documental.

Houve certa confusão na terminologia utilizada na atribuição de vasos; para Beazley, ${ }^{14}$ os termos possuíam significados bastante específicos, embora por vezes fossem compreendidos de maneira completamente diversa. Como oferecemos apenas duas possibilidades de atribuição para os vasos que não confirmamos a mão do Pintor, é preciso que se especifique o que entendemos por cada uma delas.

(13) A metodologia de análise de Beazley pode ser mais bem compreendida em alguns de seus artigos, como o "The Master of the Achilles Amphora in the Vatican", publicado no Journal of Hellenic Studies (34, 1914:179-226): "first he asks the reader to compare two red-figure lekythoi, one in Brussels, the other in Athens for shape, ornament, and composition; then to examine the legs, arms, heads and feet of the figures. Next he asks the reader to compare the legs of youth on another lekythos in Oxford with those on the first two; then the woman on the first lekythos in Brussels with a woman on a lekythos in Syracuse; then the youth on the lekythoi with those on a Nolan amphora in the British Museum, and finally the figure on the reverse of this Nolan with those on 14 other vases" (Oakley 1999:288). O que Beazley propõe é a criação de uma coleção de vasos interligados pelas características gráficas das figuras, ou parte
Aqui, 'à maneira do pintor de Gela' significa que os vasos podem ter sido produzidos moldados ou decorados - pelo próprio artista, já que se enquadram mais claramente no conjunto de detalhes atribuídos a ele: o sistema de palmetas é coerente, as formas recorrentes, os traços anatômicos similares, mesmo que tenham sofrido algumas alterações. São vasos que não podem ser claramente atribuídos ao Pintor mas também não afastados de sua produção pessoal (Figura 14).

'À oficina do pintor de Gela' define a atribuição dos vasos que possuem traços decorativos, iconográficos ou formais que os aproximam do conjunto de vasos atribuídos ao Pintor, mas não indicam claramente que eles possam ter sido produzidos ou decorados somente por ele. Significa que alguns elementos estão presentes, mas as diferenças são mais aparentes que as similaridades (Figura 15).

Acreditamos que com esta resolução eliminamos a confusão causada pela enorme quantidade de termos duvidosos ou equivocados utilizados pelos autores que atribuíram os vasos, além de permitir que grande número de vasos próximos aos produzidos pelo Pintor de Gela prosseguissem no conjunto de uma maneira menos forçada: dizer que eles pertencem à sua oficina ou foram produzidos à sua maneira permitiu que sua marca fosse observada em grande parte dos vasos que possuem muitas características em comum, mas que não podem certamente ser ligados à sua mão.

delas, que eram desenhadas quase da mesma maneira. As figuras e decoração eram ainda comparadas entre si para a observação de traços comuns nos vasos já agrupados pelo autor (Robertson 1985:27). (14) A partir de 1942, Beazley insere em suas atribuições a categoria 'à maneira' do pintor (Rouet 1999:146): "I am conscious that the vases placed under the heading 'manner of' an artist are not always in the same category: list may include (1) vases which are like the painter's work, but cannot safely be said not to be from his hand, (2) vases which are like the painter's work, but about which I do know enough to say that they are not from his hand, (3) vases which are like the painter's work, but of which, although I know them well, I cannot say whether they are from his hand or not" (in Rouet 2001:100). 
DIAS, C.K.B. Apontamentos sobre a atribuição de vasos áticos: a produção do Pintor de Gela. Revista do Museu de Arqueologia e Etnologia, São Paulo, 19: 235-255, 2009.

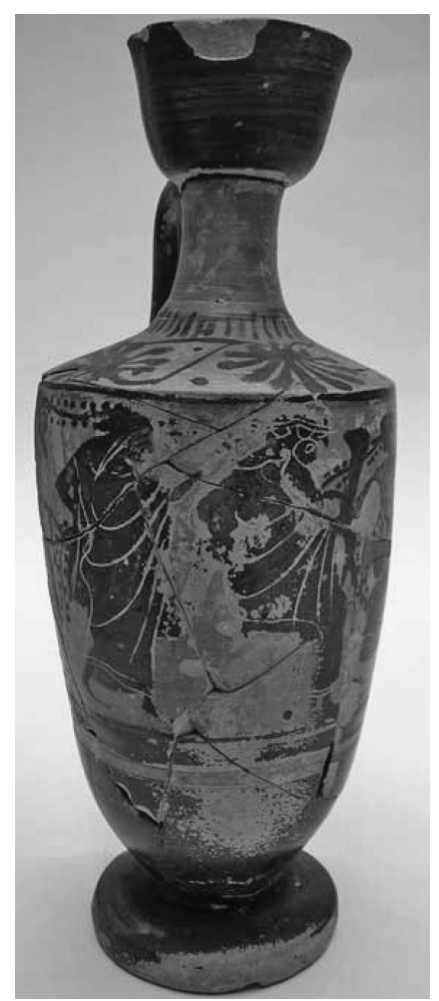

Fig. 14. Lécito Siracusa, Paolo Orsi 19890, atribuído ao P. de Gela por Haspels. Reatribuído à maneira do Pintor de Gela por Carolina Kesser.

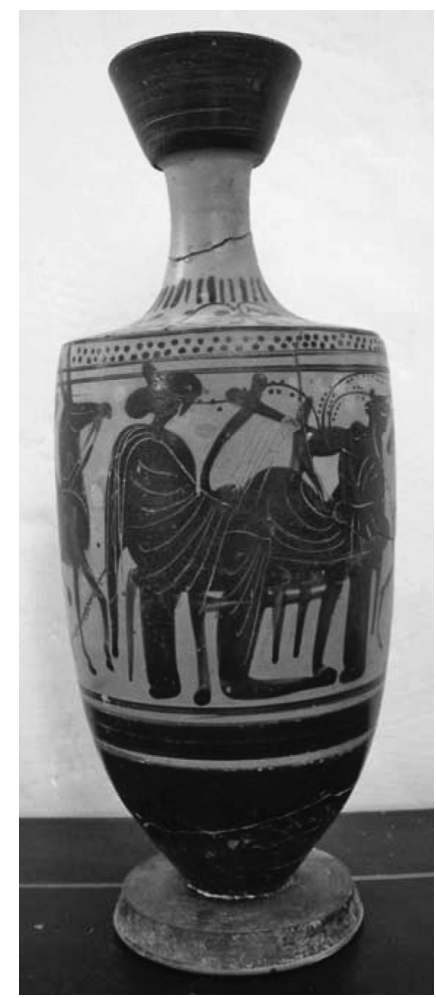

Fig. 15. Lécito Agrigento, Mus. Reg. C830, atribuído ao P. de Gela por Calderone. Reatribuído à oficina do Pintor de Gela por Carolina Kesser.

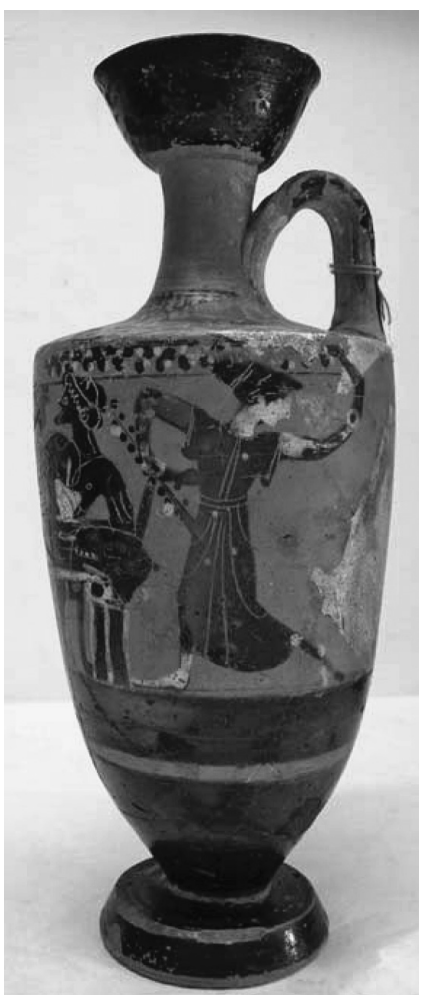

Fig. 16. Lécito Paris, Mus. do Louvre CA 2255, atribuído como "remete ao P. de Gela" por Beazley; atribuído à Classe de Atenas 581 por Beazley. Excluído do conjunto por Carolina Kesser.
Portanto, estudamos 84 vasos atribuídos de diversas maneiras (Tabela 1$)^{15}$ e os analisamos sob o ponto de vista formal, estilístico, decorativo e iconográfico, a fim de confirmarmos ou corrigirmos suas atribuições. Partimos da lista dos vasos 'ligados ao Pintor' do $A B L$ e iniciamos uma série de compara-

(15) Os 84 vasos foram distribuídos em 10 conjuntos estipulados por afinidades estilísticas, decorativas ou formais; um vaso - o esquifo Bruxelas, Musées Royaux A 1983 - foi apresentado sozinho por tratar-se de um caso específico que o excluiu: o vaso é falso (Hemelrijk 1975). Ao longo das análises, alguns outros vasos foram sendo incorporados aos conjuntos para que suas atribuições fossem corrigidas ou confirmadas, daí estarem presentes em nossa tabela 101 vasos, e não apenas os 84 originalmente destacados. ções entre eles, depois entre eles e os fichados no Arquivo Beazley $(A B)$ sob diversos termos de atribuição e, enfim, ao conjunto total. Comparamo-los aos atribuídos ao Pintor de Gela e fizemos uma nova rodada de observações.

Os vasos que não foram possíveis atribuir a uma das três categorias propostas foram excluídos do conjunto (Figura 16), e no presente momento aguardam a continuidade de nossa pesquisa, em que proporemos novas atribuições a fim de não deixá-los "órfãos”.

Os vasos estudados foram reunidos através de material publicado e durante o trabalho que desenvolvemos em museus. Várias publicações oferecem registro fotográfico satisfatório, o que permitiu que os vasos e seus detalhes fossem bem observados. Mas isso não foi uma 
Tabela 1

\begin{tabular}{|c|c|c|c|}
\hline \multicolumn{4}{|c|}{ Sistematização das informações dos 101 vasos com problemas específicos de atribuição } \\
\hline Forma & Coleção/Num. de Inv. & Atribuição/Autor & $\begin{array}{c}\text { Sistematização da } \\
\text { atribuição por } \\
\text { C.K.B.D }\end{array}$ \\
\hline $\mathrm{L}$ & Genebra Paladion AK1976 & À oficina - Desconhecido & $\grave{A}$ maneira \\
\hline L & Agrigento M. Reg. AG 22611 & Ao Pintor - De Miro & $\grave{A}$ maneira \\
\hline $\mathrm{L}$ & Genebra, M. A. e Hist. 12048 & Próximo ao P. - Yalouris & À oficina \\
\hline $\mathrm{L}$ & Munique, Staatl. Antik. 1983 & Ao Pintor - Desconhecido & $\grave{A}$ maneira \\
\hline E & Ferrara, Museu di Spina 195 & Ao Pintor - Patitucci & Ao Pintor \\
\hline $\mathrm{L}$ & Agrigento M. Reg. C830 & Ao Pintor - Calderoni & À oficina \\
\hline $\mathrm{L}$ & Taranto, M. Nac. 102585 & Próximo ao P. - Lo Porto & À maneira \\
\hline $\mathrm{L}$ & Atenas, M. Ágora P 24534 & Ligado ao P. - Beazley & À maneira \\
\hline $\mathrm{L}$ & Londres, M. Brit. 1772.3-20.2 & Ao Pintor - Haspels & À maneira \\
\hline $\mathrm{L}$ & Erbach, Graf. Samml. 21 & Ao Pintor - Heenes & À maneira \\
\hline $\mathrm{L}$ & Madri, M. Nac.19519 & Ao Pintor - Haspels & $\grave{A}$ maneira \\
\hline $\mathrm{L}$ & Bologna, M. Reg. C 52 & Ao Pintor - Haspels & À maneira \\
\hline $\mathrm{L}$ & Palermo, M. Nac. NI 42277 & Ao Pintor - Marchese & À maneira \\
\hline $\mathrm{L}$ & Palermo, M. Nac. NI 1874 & Ao Pintor - Haspels & $\grave{A}$ maneira \\
\hline $\mathrm{L}$ & Agrigento, M. Reg AG S/115 & Comparar ao P.- Desc. & À maneira \\
\hline $\mathrm{L}$ & Kunstw. der Antike 2002:227 & Ligado ao P. - Haspels & À maneira \\
\hline $\mathrm{L}$ & NY, Col. Universidade X.054 & Ao Pintor - Beazley & À maneira \\
\hline $\mathrm{L}$ & Nápoles, Col. Raccolta 86324 & Ao Pintor - Haspels & À oficina \\
\hline E & Nápoles, Mus. Mac. 164178 & Ao Pintor - Desconhecido & $\grave{A}$ maneira \\
\hline $\mathrm{L}$ & Moscou, M. Pushkin M 550 & Ao Pintor - Sidorova & À maneira \\
\hline $\mathrm{L}$ & Bochum, M. Un. Ruhr S149 & Ao Pintor - Kunisch & À maneira \\
\hline $\mathrm{L}$ & Taranto, M. Nac. 102584 & Próximo ao P. - Lo Porto & À maneira \\
\hline $\mathrm{L}$ & Atenas, M. Ágora P 24535 & Próximo ao P. - Beazley & À maneira \\
\hline $\mathrm{L}$ & Palermo, M. Nac. NI 1903 & Ao Pintor - Marchese & À maneira \\
\hline $\mathrm{L}$ & Siracusa, Paolo Orsi 19890 & Ao Pintor - Haspels & À maneira \\
\hline $\mathrm{L}$ & Gela, M. Arq. 39428 (ant. 19) & Ao Pintor - Oliveri & À maneira \\
\hline $\mathrm{L}$ & Royal Athena 118 & Lembra o P. - Desc. & $\grave{A}$ maneira \\
\hline $\mathrm{L}$ & Atenas, M. Ágora P 24537 & Ao Pintor - Beazley & À maneira \\
\hline $\mathrm{L}$ & Londres, M. Brit. 1863.7-28.8 & Ao Pintor - Haspels & À maneira \\
\hline $\mathrm{L}$ & Palermo, Banco di Sicilia 408 & $\begin{array}{l}\text { Ao Pintor - Panvini/ Classe de } \\
\text { Atenas } 851 \text { - De La Genière }\end{array}$ & À oficina \\
\hline E & Ferrara, Museu di Spina 193 & Ao Pintor - Beazley & Ao Pintor \\
\hline $\mathrm{L}$ & Siracusa, Paolo Orsi 21190 & Conectado ao P. - Haspels & $\grave{A}$ maneira \\
\hline $\mathrm{L}$ & Gela, M. A. Navarra 40215 & Ao Pintor - Haspels & À maneira \\
\hline $\mathrm{L}$ & Agrigento Mus. Reg. C 845 & Ao Pintor - Haspels & À maneira \\
\hline $\mathrm{L}$ & Bari, Bassano del Grappa 45 & Próximo ao P. - Andreassi & À oficina \\
\hline $\mathrm{L}$ & Ostwestfalen, D.J. & Ao Pintor - Stähler & À oficina \\
\hline $\mathrm{L}$ & Heidelberg L 66 & À maneira - Gropengiesser & À maneira \\
\hline $\mathrm{L}$ & Gela, M. A. Navarra 40216 & Ligado ao P. - Haspels & À oficina \\
\hline $\mathrm{L}$ & Bruxelas, M. Royaux R271 & $\begin{array}{l}\text { Ligado ao P. - Haspels/ À } \\
\text { maneira P. de Hémon - Beazley }\end{array}$ & À oficina \\
\hline $\mathrm{L}$ & Corinto, Museu Arq. T 1074 & Ligado ao P. - Haspels & À oficina \\
\hline $\mathrm{L}$ & Atenas, M. Ágora P 24533 & Ligado ao P. - Beazley & À maneira \\
\hline
\end{tabular}


Tabela 1 (cont.)

Sistematização das informações dos 101 vasos com problemas específicos de atribuição

Forma Coleção/Num. de Inv.

Atribuição/Autor

Sistematização da

atribuição por

C.K.B.D

\begin{tabular}{|c|c|c|c|}
\hline $\mathrm{L}$ & Agrigento, M. A. 6808 & Ao Pintor - De Miro & À maneira \\
\hline $\mathrm{L}$ & Catania, Benedittini 4069 & Ao Pintor - Haspels & À maneira \\
\hline $\mathrm{L}$ & Oslo, M. Etnográfico 5814 & Ligado ao P. - Seeberg & À oficina \\
\hline $\mathrm{L}$ & Atenas, M. Ágora P 24536 & Ligado ao P. - Beazley & À maneira \\
\hline $\mathrm{L}$ & Paris, M. do Louvre F 434 & Ao Pintor - Haspels & À maneira \\
\hline $\mathrm{L}$ & Oslo, M. Etnográfico 11074 & Ao Pintor - Seeberg & À oficina \\
\hline $\mathrm{L}$ & Detroit, Inst. de Artes 24.122 & À maneira - Madigan & À maneira \\
\hline $\mathrm{L}$ & Berlim, Col. Privada 78 & Ao Pintor - Vierneisel & À oficina \\
\hline $\mathrm{O}$ & Adria, M. Nac. Bocchi A 106 & Ao Pintor - Bonomi & À maneira \\
\hline $\mathrm{L}$ & Siracusa, Paolo Orsi 19823 & Ligado ao P. - Haspels & À oficina \\
\hline $\mathrm{E}$ & Ferrara, Museu di Spina 196 & Ao Pintor - Beazley & Ao Pintor \\
\hline $\mathrm{L}$ & Paris M.do Louvre Cp 10829 & Ao Pintor - Beazley & À maneira \\
\hline $\mathrm{L}$ & Amsterdam, Privada & Ao Pintor - Hemelrijk & À oficina \\
\hline $\mathrm{L}$ & Agrigento, M. A. AG 22184 & Comparar ao P. - De Miro & À maneira \\
\hline E & Ferrara, Museu di Spina 200 & Próximo ao P. - Beazley & À maneira \\
\hline $\mathrm{L}$ & Londres, M. Brit. 1905.7-11.1 & Ao Pintor - Beazley & À maneira \\
\hline $\mathrm{L}$ & Desconhecido, ex-Englefield & Ao Pintor - Haspels & À maneira \\
\hline E & Copenhague M. Nac. 69 & Próximo ao P. - Beazleu & Ao Pintor \\
\hline $\mathrm{L}$ & NY, Royal Athena 1998, 25 & Ao Pintor - Desconhecido & À maneira \\
\hline $\mathrm{L}$ & Palermo, M. Nac. NI 1859 & Ao Pintor - Haspels & À oficina \\
\hline $\mathrm{L}$ & Palermo, Col. Mormino 137 & Ao Pintor - De la Genière & À oficina \\
\hline $\mathrm{L}$ & Basiléia, Antikenmus. Z 377 & Ao Pintor - Beazley & À oficina \\
\hline $\mathrm{L}$ & Agrigento, M. A. R 149 & Ao Pintor - Haspels & À oficina \\
\hline $\mathrm{L}$ & Olimpia, M. Arq. K 10874 & Ao Pintor - Burrow & À oficina \\
\hline E & Paris, M. do Louvre F162 & $\begin{array}{l}\text { Ao Pintor - Haspels/ Ao P. de } \\
\text { Edimburgo - Haspels }\end{array}$ & Ao Pintor \\
\hline E & NY, Metropolitan 06.1021.70 & $\begin{array}{l}\text { Ao Pintor - Haspels/ Ao P. de } \\
\text { Edimburgo - Haspels }\end{array}$ & Ao Pintor \\
\hline $\mathrm{L}$ & Dinamarca, M. Thorv. H553 & Conectado ao P.- Melander & $\grave{A}$ maneira \\
\hline $\mathrm{L}$ & Adria, M. N. Bocchi 22803 & Ao Pintor - Bonomi & À oficina \\
\hline $\mathrm{L}$ & Londres, M.B. 1863.7-28.352 & Ao Pintor - Haspels & À maneira \\
\hline $\mathrm{L}$ & Adria, M. Nac. 22783 & Ao Pintor - Bonomi & À oficina \\
\hline $\mathrm{L}$ & Olimpia M. Arq. K 10877 & Ao Pintor - Burrow & Ao Pintor \\
\hline E & Ferrara, M. di Spina 198 & Próximo ao P. - Beazley & Ao Pintor \\
\hline $\mathrm{E}$ & Ferrara, M. di Spina 16353 & Ao Pintor - Beazley & Ao Pintor \\
\hline $\mathrm{E}$ & Ferrara, M. di Spina 197 & Ao Pintor - Beazley & Ao Pintor \\
\hline E & Ferrara, M. di Spina 194 & Próximo ao P. - Beazley & À maneira \\
\hline E & Adria, M. Arq. Nac. 22457 & Ao Pintor - Bonomi & Ao Pintor \\
\hline L & Glasgow, Col. A. 1902.73AO & Comparar ao P. - Moignard & À oficina \\
\hline $\mathrm{L}$ & Palermo, Col. Mormino 1356 & Ao Pintor - Desconhecido & Ao Pintor \\
\hline L & Gela, Mus. Arqueológico 15 & Ao Pintor - Panvini & Excluído do conjunto \\
\hline $\mathrm{L}$ & Agrigento, M. Nac. S30 & Comparar ao P. - De Miro & Excluído do conjunto \\
\hline $\mathrm{L}$ & Taranto, M. Nac. 4415 & Próximo ao P. - Amicis & Excluído do conjunto \\
\hline
\end{tabular}


Tabela 1 (cont.)

\begin{tabular}{|c|c|c|c|}
\hline \multicolumn{4}{|c|}{ Sistematização das informações dos 101 vasos com problemas específicos de atribuição } \\
\hline Forma & Coleção/Num. de Inv. & Atribuição/Autor & $\begin{array}{l}\text { Sistematização da } \\
\text { atribuição por } \\
\text { C.K.B.D }\end{array}$ \\
\hline $\mathrm{L}$ & Hamburgo, M.K.G. 1909.176 & Talvez ao P. - Brummer & Excluído do conjunto \\
\hline $\mathrm{L}$ & Agrigento, M. R. AG 22610 & Ao Pintor - De Miro & Excluído do conjunto \\
\hline E & Dinamarca, M. Thorv. H 528 & $\begin{array}{l}\text { A comparar com Altenburg } \\
\text { Class, Pintor de Atena e Pintor } \\
\text { de Gela - Melander }\end{array}$ & Excluído do conjunto \\
\hline E & Copenhague, M. Nac. 835 & Ao Pintor - Desconhecido & Excluído do conjunto \\
\hline $\mathrm{O}$ & Praga, M. Nac. 1740 & Próximo ao P. - Dufková & Excluído do conjunto \\
\hline $\mathrm{L}$ & Adria, M. Nac. 22784 & Ao Pintor - Bonomi & Excluído do conjunto \\
\hline $\mathrm{L}$ & Adria, M. Nac. 23501 & Ao Pintor - Bonomi & Excluído do conjunto \\
\hline $\mathrm{L}$ & Atenas, M. Cer. HS 65/125 & Ao Pintor - Knigge & Excluído do conjunto \\
\hline $\mathrm{L}$ & Bari, M. Caltanissetta 712 & Ao Pintor - Panvini & Excluído do conjunto \\
\hline $\mathrm{L}$ & Morlanwelz,Mariemont 568B & Ao Pintor - Desconhecido & Excluído do conjunto \\
\hline S & Bruxelas, M. Royaux A 1983 & Ao Pintor - Bakalakis & Excluído do conjunto \\
\hline $\mathrm{L}$ & Laon, M. Mun. 37890 & $\begin{array}{l}\text { À maneira - Bothmer/ Grupo } \\
\text { de Phanyllis - Beazley }\end{array}$ & Excluído do conjunto \\
\hline $\mathrm{L}$ & Bari, M. Caltanissetta 830 & Ao Pintor - Panvini & Excluído do conjunto \\
\hline $\mathrm{L}$ & Taranto, M. Nac. 52320 & Próximo ao P. - Amicis & Excluído do conjunto \\
\hline $\mathrm{L}$ & S.Petersburgo, Hermitage 149 & Ao Pintor - Gorbunova & Excluído do conjunto \\
\hline $\mathrm{L}$ & Agrigento, M. R. AG 22145 & Próximo ao P. - De Miro & Excluído do conjunto \\
\hline $\mathrm{L}$ & Atenas, M. Cer. HS 65/215 & Ao Pintor - Knigge & Excluído do conjunto \\
\hline $\mathrm{L}$ & Paris, M. do Louvre CA 2255 & $\begin{array}{l}\text { Remete ao P. - Beazley/Classe } \\
\text { de Atenas } 581 \text { - Beazley }\end{array}$ & Excluído do conjunto \\
\hline $\mathrm{L}$ & Himera, M.Civico H 71.532,2 & Talvez ao P. - Carra & Excluído do conjunto \\
\hline
\end{tabular}

Legenda: (L) lécito; (E) enócoa; (O) olpa; (S) esquifo.

regra: muitas fontes, a maioria, devemos dizer, não oferecem fotografias dos quatro giros e detalhamento do ombro, por exemplo; algumas fornecem apenas uma foto do vaso, de um detalhe ou de só uma face, ou apenas do campo figurado, o que impediu a análise do sistema de palmetas e da forma do vaso. Algumas fotografias impediram que uma análise satisfatória fosse feita porque elas eram de baixa qualidade, borradas e até mesmo fora de foco; algumas publicações ofereceram apenas desenhos da cena figurada. Para esses casos foi preciso que confiássemos nas descrições fornecidas no texto, apesar da irregularidade na publicação das informações. Fizemos o possível para extrair dados confiáveis dos poucos registros que pudemos reunir sobre alguns vasos e aguardamos que novas publicações ou novas oportunidades de trabalho empírico possam resolver alguns desses problemas causados pela divulgação de dados e imagens.

Após o estudo dos vasos selecionados com problemas específicos, a sistematização resultou em:

-12 vasos atribuídos ao Pintor de

Gela (que, somados aos 164 restantes, totalizaram 176 vasos atribuídos a uma mesma mão);

- 46 vasos atribuídos à maneira do

Pintor de Gela;

-22 vasos atribuídos à oficina do

Pintor de Gela;

-22 vasos excluídos. 
DIAS, C.K.B. Apontamentos sobre a atribuição de vasos áticos: a produção do Pintor de Gela. Revista do Museu de Arqueologia e Etnologia, São Paulo, 19: 235-255, 2009.

\section{Conclusões}

A sistematização que promoveu a composição de conjuntos de vasos com características coesas contribuiu para um maior entendimento das características formais, decorativas e iconográficas de nosso artista. Daí, através de comparações com vasos atribuídos a outros artistas, foi possível que melhor contextualizássemos sua obra em um meio sócio-produtivo específico. A relação entre esses vasos e o meio produtivo contemporâneo é aqui entendida, sobretudo, enquanto trabalho compartilhado e influências entre artistas em um mesmo momento, ou em uma mesma oficina, ou em um mesmo objeto.

Alguns vasos de nosso conjunto foram também relacionados e atribuídos a outros artistas, como o Pintor de Hémon, o Pintor de Edimburgo e o Pintor do Atena 851. Porém, acreditamos que, em alguns casos, a outra atribuição demonstre mais uma possibilidade de relação entre as personalidades artísticas (e suas oficinas) do que um erro de interpretação. Em outras palavras, os vasos não necessariamente se afastam da produção do Pintor de Gela ao se aproximarem de outros Pintores.

Há que se lembrar que Haspels atribuiu vasos a diversos artistas que, em algum momento, relacionam-se formal, decorativa ou iconograficamente e, ao entendermos esse círculo de influências, tornou-se possível aproximarmos nosso artista de outros artistas contemporâneos. Sugerimos, portanto, que nosso artista possa ter trabalhado com grande grau de conexão a outros artistas, como o Pintor de Edimburgo e o Pintor de Hémon, e que essas relações poderão ser mais bem atestadas quando conhecermos mais profundamente as características de cada um dos outros artistas. Mas, até o momento, acreditamos ser possível relacioná-los enquanto colaboradores, mesmo se essa colaboração se limitar ao campo das influências formais ou iconográficas.

Portanto, torna-se um fato que, em algum momento ou em alguma circunstância, alguns vasos sejam aproximados ou mesmo atribuídos a mais de um artista, o que, ao contrário de descreditar o trabalho atributivo, o reforça, permitindo o estabelecimento de relações artísticas e sociais, com implicações reais de trabalho conjunto nas oficinas.

Em nossa pesquisa, conhecer uma personalidade artística individualmente foi um passo essencial para os questionamentos sobre as relações entre artistas; é a partir da caracterização dos indivíduos que poderemos estabelecer comparações entre produções, inclusive sob o ponto de vista da influência e da colaboração. Nossa caracterização do Pintor de Gela demonstrou que ele, além de possuir preocupações técnicas inerentes à sua produção, está completamente contextualizado no meio artístico e produtivo de seu tempo, produzindo uma grande quantidade de material que pode ser relacionado a outros artistas e contextos, sobretudo quando lembramos que boa parte de sua obra foi encontrada fora da Ática, o que também o insere no universo dos mecanismos comerciais.

Contudo, essas atribuições, e consequentes relações, só podem ser feitas a partir da observação dos traços de maneira objetiva, levando-se em conta os dados estilísticos, formais, cronológicos e iconográficos, de maneira a evitar interpretações subjetivas que demonstrem que as relações entre artistas só podem ocorrer enquanto emulação, aprendizado ou cópia.

DIAS, C.K.B. Notes on the attribution of Attic vases: the Gela Painter's production. Revista do Museu de Arqueologia e Etnologia, São Paulo, 19: 235-255, 2009.

Abstract: At the beginning of the 20th Century, J. D. Beazley cast the definite foundations to the attribution methodology of Attic vases. Throughout the years, the ceramic vases were linked to the hands of artists conventionally named, as the Gela Painter, an Attic artist who worked in Athens from the end of the 6th 
Century to the middle of the 5th Century B.C., thus named because the larger amount of his vases was found in Sicily, especially in Gela. Over 350 vases were linked to this painter, attributed in many ways to his own hands, his manner and his workshop. However, some of these attributions have been presented in an imprecise or, in fact, mistaken way. We systematize and correct them, in order to comprehend this artist's production fully, inserted on the context of the Attic ceramic production of his period.

Keywords: Attic pottery - Black figures - Gela Painter - Attribution.

\section{Referências bibliográficas}

BEAZLEY, J.D.

1956 Attic black figure vase painters. Oxford: Clarendon Press.

1971 Paralipomena. Additions to Attic black-figure vase-painters and to Attic red-figure vasepainters. Oxford: Clarendon Press.

BOARDMAN J.

1991 Athenian black figure vases. A handbook. London: Thames and Hudson.

DIAS, C.K.B.

2009 O Pintor de Gela. Características formais e estilísticas, decorativas e imagéticas. Tese de Doutorado. São Paulo: Universidade de São Paulo, 2009.

HASPELS, C.H.E.

1936 Attic black-figured lekythoi. Paris: E. de Boccard.

HEMELRIJK, J.M.

1974 The Gela Painter in the Allard Pierson Museum. BABesch, XLIX: 117-158.

1975 Notes on some forgeries of Greek Vases. BABesch, L: 265-280.

FRONTISI-DUCROUX, F.

1996 Quelques remarques sur le peintre de Gela. Estratto da I Vasi Attici ed Altre Ceramiche Coeve in Sicilia. Vol. I. Catania: Consiglio Nazionale Delle Richerche. Centro di Studio Sull'Archeologia Greca: 191-199.
OAKLEY, J.

1999 "Through a glass darkly I": some misconceptions about the study of greek vase-painting. Proceedings of the $\mathrm{XV}$ th international congress of classical archaeology, Amsterdam, 12-17 jul. 1998, Classical Archaeology towards the $3^{\text {rd }}$ Millenium: Reflections and Perspectives. Allard Pierson: 286-289.

ROBERTSON, M.A.

1976 The Beazley archive. Archeologia Classica, XXVIII: 310-311

1985 Beazley and Attic vase painitng. In: Kurtz, D. (Ed.) Beazley and Oxford. Lectures delivered at Wolfson College, Oxford on 28 June, 1985. Monograph 10.

Oxford: University Committee for Archaeology: 19-30.

ROUET, PH.

1999 Ateliers et écoles picturales chez Beazley. Les changements d'atribuition. Céramique et Peinture Grecques Modes d'emploi. Actes du Colloque International, École du Louvre 26-28 avr., 1995, Paris: 45-153.

2001 Approaches to study of attic vases. Beazley and Pottier. Oxford: Oxford Monographs, Oxford University Press. 